\title{
Synthesis of Some New Mono, Bis-Indolo[1, 2-c]quinazolines: Evaluation of their Antimicrobial Studies
}

\author{
Rondla Rohini, ${ }^{a, c}$ P. Muralidhar Reddy, ${ }^{a, b}$ Kanne Shanker, ${ }^{a}$ \\ Anren $\mathrm{Hu}^{*, c}$ and Vadde Ravinder $*, a$ \\ ${ }^{a}$ Department of Chemistry, Kakatiya University, Warangal-506 009, A.P, India \\ ${ }^{b}$ Department of Chemistry, National Dong Hwa University, Hualien, Taiwan \\ ${ }^{c}$ Department of Laboratory Medicine and Biotechnology, Tzu Chi University, Hualien, Taiwan
}

\begin{abstract}
Uma estratégia conveniente em três etapas é proposta para a síntese de mono e bis-indolo[1,2-c] quinazolinas, a partir de 2-(2-aminofenil)indol e aril aldeídos. Os novos compostos sintetizados foram caracterizados por análise elementar, IV, ${ }^{1} \mathrm{H} \mathrm{RMN},{ }^{13} \mathrm{C} \mathrm{RMN}$, e espectrometria de massa. Todos os derivados foram testados para avaliação das suas atividades antibacterial ( $S$. aureus, B. subtilis, S. pyogenes, S. typhimurium, E. coli, K. pneumonia) e antifúngica (A. niger, C. albicans, T. viridae) usando o método cup plate. Dentre os compostos testados, as mono- indolo[1,2-c] quinazolinas (15-18) exibiram boas atividades antibacteriais, enquanto 15 e 18 também mostraram notável atividade antifúngica. Especialmente, 19 e 20 exibiram forte atividade antibacteriana e antifúngica contra todas as cepas testadas.
\end{abstract}

A convenient three-step strategy is proposed for the synthesis of mono and bis-indolo[1,2-c] quinazolines from 2-(2-aminophenyl)indole and various aryl aldehydes. The newly synthesized compounds were characterized by elemental analysis, IR, ${ }^{1} \mathrm{H}$ NMR, ${ }^{13} \mathrm{C} \mathrm{NMR}$, and mass spectroscopic investigation. All the derivatives were screened for antibacterial (S. aureus, B. subtilis, S. pyogenes, S. typhimurium, E. coli, K. pneumonia) and antifungal (A. niger, C. albicans, T. viridae) activities by cup plate method. Among the compounds tested, mono- indolo[1,2-c] quinazolines (15-18) exhibited good antibacterial activities while $\mathbf{1 5}$ and $\mathbf{1 8}$ also showed notable antifungal activity. Especially, $\mathbf{1 9}$ and $\mathbf{2 0}$ exhibited stronger antibacterial as well as antifungal activity against all tested strains.

Keywords: indolo[1,2-c]quinazolines, synthesis, antibacterial activity, antifungal activity

\section{Introduction}

The indole is a crucial heterocyclic skeleton often associated with pharmacological properties. ${ }^{1,2}$ It is a fundamental constituent of a number of natural and synthetic products with biological activity. ${ }^{3,4}$ Due to the structural similarity of indole nuclei with some naturally occurring compounds such as serotonin, tryptamine, hinckdentine A, they can easily interact with biomolecules of the living systems. ${ }^{5,6}$ Heterocycles bearing an indole moiety are reported to show a broad spectrum of pharmacological and medicinal properties such as anti-inflammatory, ${ }^{7,8}$ anticonvulsant, ${ }^{9}$ antimicrobial, ${ }^{10,11}$ antimalarial,,$^{12,13}$ anticancer ${ }^{14,15}$ and many other activities.

*e-mail: anren@mail.tcu.edu.tw; ravichemku@ rediffmail.com
The introduction of an additional substituent on the indole nuclei has been increasing attention in the expectation that such changes could potentially affect the interaction of the molecules with biological targets. Fused cyclic indole derivatives, such as indolocarbazoles, ${ }^{16,17}$ indolo[2,3-b] quinolines, ${ }^{18,19}$ indolo[1,2-c] quinazolines, ${ }^{20,21}$ bis-indoles ${ }^{22,23}$ and many others, have also interesting pharmacological properties. Moreover, indoles and their cyclic derivatives constitute an important class of compounds for new drug development in order to discover an effective compound against multi-drug-resistant microbial infections. Recently, Gurkok et al. ${ }^{24}$ synthesized a series of indole-3-aldehyde and 5-bromoindole-3-aldehyde hydrazide and hydrazones and evaluated for their in vitro antimicrobial activities using the 2-fold serial dilution technique. Very recently, a series of 2-o-arylidineaminophenylindoles and their 
cyclic derivatives were synthesized and evaluated for their antibacterial as well as antifungal activities. ${ }^{25}$ These observations have encouraged us to synthesize some new products containing the indole moiety hoping to obtain new compounds with potential biological activity. At last, we have succeeded in the preparation of several new indolo[1,2-c]quinazolines derivatives, which are structurally related to terrestrial or marine alkaloids (e.g. hinckdentine A). In addition all the newly synthesized quinazolines were screened for their in vitro antimicrobial activity.

\section{Results and Discussion}

\section{Chemistry}

The indolo[1,2-c]quinazoline ring system was first prepared in 1956 by Kiang et al. ${ }^{26}$ and Cava and Billimoria ${ }^{27}$ have reviewed the chemistry of indoloquinazolines, which are uncommon in nature. Moreover, they have published an interesting approach to the synthesis of hinckdentine $\mathrm{A}$ and other indolo[1,2-c]quinazoline derivatives. ${ }^{5}$ Frere et al. ${ }^{28}$ have developed a successful microwave assisted strategy for the synthesis of novel 6-substituted indolo[1,2-c] quinazolines by the condensation of 2-(2-aminophenyl) indole with 2-cyanobenzothiazoles. Molina et al. ${ }^{29}$ reported the synthesis of indolo[1,2-c] quinazolines via iminophosphoranes.

In the present investigation, a convenient three-step strategy has been developed for the synthesis of mono and bis-indolo[1,2-c]quinazolines using 2-(2-aminophenyl) indole (A) as a key compound (Scheme 1). The required starting material A was prepared by the Fischer indole synthesis from phenylhydrazine hydrochloride and 2-amino acetophenone using a mixture of methane sulfonic acid and phosphorus pentoxide. ${ }^{5}$ The condensation of 2-(2-aminophenyl)indole (A) with different aromatic aldehydes (Ar-CHO/CHO-Ar-CHO), yielded mono and bis-2-(2-arylideneaminophenyl)indoles, which on treatment with powdered $\mathrm{KMnO}_{4}$ in acetone furnished mono and bis-indolo[1,2-c]quinazolines in good yields. The structural assignments to the new compounds were based on their elemental analysis and spectral (IR, ${ }^{1} \mathrm{H}$ NMR, ${ }^{13} \mathrm{C}$ NMR and mass) data.

The IR spectrum of 2-(2-aminophenyl)indole (A) exhibited an absorption band at $3380-3440 \mathrm{~cm}^{-1}$ due to the amino phenyl ring. All 2-(2-arylideneaminophenyl)indole intermediates (1-10) and precursor A exhibit characteristic IR absorption bands in the regions $3330-3400 \mathrm{~cm}^{-1}$ and $1540-1560 \mathrm{~cm}^{-1}$ indicative of $-\mathrm{NH}$ stretching and bending vibrations of indole ring, respectively. ${ }^{30}$ The formation of intermediate azomethines (1-10) was identified by

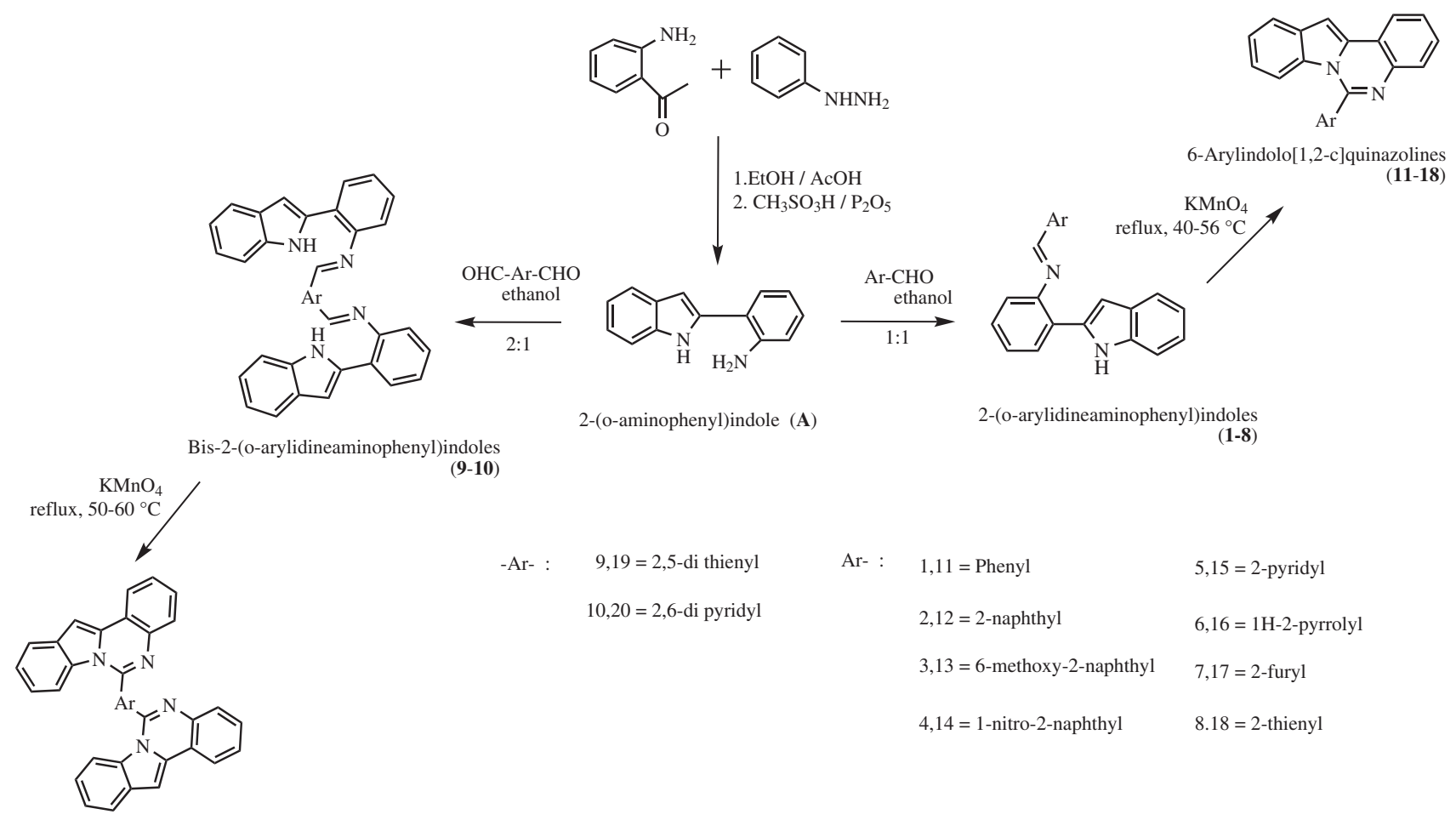

Bis-6-Arylindolo[1,2-c]quinazolines

(19-20)

Scheme 1. Synthesis of 6-arylindolo[1,2-c]quinazolines (11-20). 
disappearance of peaks at $1680-1695 \mathrm{~cm}^{-1}$ for $-\mathrm{CHO}$ and $3380-3440 \mathrm{~cm}^{-1}$ for $-\mathrm{NH}_{2}$ of starting materials and at the same time appearance of band at $1610-1635 \mathrm{~cm}^{-1}$ which is characteristic for $-\mathrm{CH}=\mathrm{N}$ group. ${ }^{31}$ The formation of title compounds (11-20) were confirmed by the disappearance of the absorption maxima at $3330-3400 \mathrm{~cm}^{-1}$, which are ascribed to the vibrations of $\mathrm{NH}$ group of the indole ring; at the same time the appearance of a new maximum at $1360-1380 \mathrm{~cm}^{-1}$, which is characteristic for indolo[1,2-c] quinazoline ring with a tertiary nitrogen atom, appears. ${ }^{32}$

The exhibited chemical shifts obtained from ${ }^{1} \mathrm{H}$ NMR spectra of compounds 1-20 supported the proposed structures of the compounds. ${ }^{1} \mathrm{H}$ NMR of $\mathbf{A}$ showed a singlet at $\delta 6.4 \mathrm{ppm}$, characteristic for $-\mathrm{NH}_{2}$ group of amino phenyl ring and other singlet at $\delta 8.48 \mathrm{ppm}$, characteristic for $-\mathrm{NH}$ group of indolyl ring. ${ }^{16}$ The condensation between A and aldehydes (a-j) was confirmed by the disappearance of signals at $\delta 6.4$ corresponding to $\mathrm{NH}_{2}$ protons of compound $\mathbf{A}$ and appearance of signals at $\delta$ 8.16-8.29 which is due to $\mathrm{CH}=\mathrm{N}$ protons. Finally, in the title compounds disappearance of signals corresponding to $-\mathrm{NH}$ of indolyl ring and $\mathrm{CH}=\mathrm{N}$ protons supports the indoloquinazoline ring structure. ${ }^{32}$

Further, ${ }^{13} \mathrm{C}$ NMR spectra showed confirmatory signals of the $\mathrm{C}=\mathrm{N}$ carbon atoms and the aromatic carbons in the range of 148.9-167.9 ppm and 110.7-157.9 ppm respectively. ${ }^{33}$

The structures of all intermediates and title compounds were further confirmed by mass spectral analysis. ESI-MS spectra of all the compounds showed a single peak suggesting the molecular formulae. In addition, the FAB mass spectrum of compound (11) shows a parent peak at $m / z(M+) 294(100 \%)$, which confirms the proposed formula $\mathrm{C}_{21} \mathrm{H}_{14} \mathrm{~N}_{2}$. The major fragments were observed at $\mathrm{m} / \mathrm{z}$ values of $217(34.5 \%), 192(65.2 \%), 191(85.5 \%)$, $179(48.2 \%), 77(12.5 \%)$ and $76(22.8 \%)$ which indicate the fragmentation pattern of compound $\mathbf{1 1}$.

\section{Biological study}

\section{Antimicrobial activity}

All the newly synthesized quinazolines were evaluated for their in vitro antimicrobial activity against $S$. aureus, B. subtilis, S. pyogenes (Gram positive), S. typhimurium, E. coli, K. pneumonia (Gram negative) bacterial strains and A.niger, C. albicans, T. viridae fungal strains by cup plate method. ${ }^{34-36}$ Ampicillin and Ketoconazole were used as standard drugs for bacteria and fungi respectively. Preliminary screening of quinazolines and standard drugs were performed at fixed concentrations of $1000 \mu \mathrm{g} \mathrm{mL}^{-1}$. Inhibition was recorded by measuring the diameter of the inhibition zone at the end of $24 \mathrm{~h}$ for bacteria and $72 \mathrm{~h}$ for fungi. Each experiment was repeated thrice and the average of the three independent determinations was recorded. Screening results are summarized in Table 1. The antimicrobial screening revealed that some of the compounds (15-20) showed high activity against all bacterial and fungal strains. In particular, bis-indolo[1,2-c] quinazolines (19 and 20) showed excellent activity against all tested strains.

\section{Determination of minimum inhibitory concentration (MIC)}

The minimum inhibitory concentration of potent compounds (15-20) against all bacterial and fungal strains was determined by liquid dilution method. ${ }^{34-36}$ Stock solutions of tested compounds with 2.5, 5, 10, 15, 20, 25, $30,35,40,45$ and $50 \mu \mathrm{g} \mathrm{mL}^{-1}$ concentrations were prepared with appropriate solvent. The solutions of standard drugs, Ampicillin and Ketoconazole were prepared in the same concentrations. Inoculums of the bacterial and fungal culture were also prepared. To a series of tubes containing $1 \mathrm{~mL}$ each of quinazoline compound solution with different concentrations and $0.2 \mathrm{~mL}$ of the inoculums was added. Further $3.8 \mathrm{~mL}$ of the sterile water was added to each of the test tubes. These test tubes were incubated for $24 \mathrm{~h}$ and observed for the presence of turbidity. This method was repeated by changing quinazoline compounds with standard drugs Ampicillin and Ketoconazole for comparison. The minimum inhibitory concentration at which no growth was observed was taken as the MIC values (Table 2). The comparison of the MICs (in $\mu \mathrm{g} \mathrm{mL}^{-1}$ ) of potent compounds and standard drugs against tested strains are presented in Figure 1. It was found that $\mathbf{1 5 - 1 8}$ compounds have highest activity against all bacterial and fungal strains with MIC value (2.5-15 $\left.\mathrm{g} \mathrm{mL}^{-1}\right)$. Furthermore, bis-indolo[1,2-c] quinazolines (19 and 20) exhibited potent inhibitory activity (MIC range 2.5-5 $\mu \mathrm{g} \mathrm{mL}^{-1}$ ) against all the bacterial and fungal strains even than standard drugs Ampicillin and Ketoconazole.

\section{Conclusions}

In this report, easy and useful method to obtain biologically active mono and bis-6-substituted indolo[1,2-c]quinazoline derivatives have been presented and all the synthesized compounds were screened for their antimicrobial activity against different bacterial and fungal strains. From the antimicrobial data it seems that compounds which contain two quinazoline moieties in their structures (19 and 20) and heterocyclic moiety at $\mathrm{C}_{6}$ position (15-20) seem to be more potent even than standard drugs ampicillin and ketoconazole. 
Table 1. Zone of inhibition of newly synthesized 6-arylindolo[1,2-c]quinazolines (11-20) against different bacteria and fungi

\begin{tabular}{|c|c|c|c|c|c|c|c|c|c|}
\hline \multirow{3}{*}{$\begin{array}{l}\text { Compound } \\
\left(1000 \mu \mathrm{g} \mathrm{mL}^{-1}\right)\end{array}$} & \multicolumn{9}{|c|}{ Zone of inhibition / mm } \\
\hline & \multicolumn{3}{|c|}{ Gram-positive bacteria } & \multicolumn{3}{|c|}{ Gram-negative bacteria } & \multicolumn{3}{|c|}{ Fungi } \\
\hline & S. aureus & B. subtilis & S. pyogenes & S. typhimurium & E. coli & K. pneumonia & A. niger & C. albicans & T. viridae \\
\hline 11 & 21 & 15 & 18 & 12 & 20 & 18 & 21 & 20 & 18 \\
\hline 12 & 18 & 19 & 14 & 18 & 15 & 9 & 15 & 19 & 18 \\
\hline 13 & 9 & 20 & 21 & 21 & 12 & 21 & 18 & 16 & 12 \\
\hline 14 & 12 & 16 & 13 & 19 & 19 & 19 & 14 & 21 & 11 \\
\hline 15 & 48 & 50 & 48 & 49 & 51 & 50 & 46 & 48 & 45 \\
\hline 16 & 51 & 49 & 46 & 50 & 48 & 49 & 49 & 50 & 50 \\
\hline 17 & 49 & 46 & 50 & 46 & 45 & 50 & 50 & 49 & 46 \\
\hline 18 & 50 & 51 & 49 & 51 & 50 & 50 & 48 & 50 & 49 \\
\hline 19 & 52 & 52 & 51 & 55 & 52 & 51 & 52 & 51 & 55 \\
\hline 20 & 55 & 48 & 50 & 52 & 51 & 49 & 50 & 52 & 51 \\
\hline Std & $48^{\mathrm{a}}$ & $39^{\mathrm{a}}$ & $35^{\mathrm{a}}$ & $45^{\mathrm{a}}$ & $40^{\mathrm{a}}$ & $45^{\mathrm{a}}$ & $45^{\mathrm{b}}$ & $40^{\mathrm{b}}$ & $41^{\mathrm{b}}$ \\
\hline
\end{tabular}

${ }^{a} A$ mpicillin; ${ }^{b}$ Ketoconazole.

Table 2. MIC values of potent 6-arylindolo[1,2-c]quinazolines (15-20) and standard drugs

\begin{tabular}{|c|c|c|c|c|c|c|c|c|c|}
\hline \multirow{3}{*}{ Compound } & \multicolumn{9}{|c|}{$\mathrm{MIC} /\left(\mu \mathrm{g} \mathrm{mL}^{-1}\right)$} \\
\hline & \multicolumn{3}{|c|}{ Gram-positive bacteria } & \multicolumn{3}{|c|}{ Gram-negative bacteria } & \multicolumn{3}{|c|}{ Fungi } \\
\hline & S. aureus & B. subtilis & S. pyogenes & S. typhimurium & E. coli & K. pneumonia & A. niger & C. albicans & T. viridae \\
\hline 15 & 10 & 2.5 & 10 & 10 & 5 & 2.5 & 10 & 15 & 15 \\
\hline 16 & 2.5 & 10 & 15 & 5 & 10 & 5 & 10 & 5 & 5 \\
\hline 17 & 5 & 10 & 2.5 & 10 & 15 & 5 & 2.5 & 15 & 10 \\
\hline 18 & 5 & 2.5 & 5 & 5 & 5 & 5 & 5 & 5 & 5 \\
\hline 19 & 2.5 & 2.5 & 2.5 & 2.5 & 2.5 & 2.5 & 2.5 & 5 & 2.5 \\
\hline 20 & 2.5 & 5 & 5 & 2.5 & 5 & 2.5 & 5 & 2.5 & 5 \\
\hline Std & $10^{\mathrm{a}}$ & $20^{\mathrm{a}}$ & $25^{\mathrm{a}}$ & $10^{\mathrm{a}}$ & $15^{\mathrm{a}}$ & $10^{\mathrm{a}}$ & $15^{\mathrm{b}}$ & $25^{\mathrm{b}}$ & $20^{\mathrm{b}}$ \\
\hline
\end{tabular}

${ }^{a}$ Ampicillin; ${ }^{b}$ Ketoconazole.

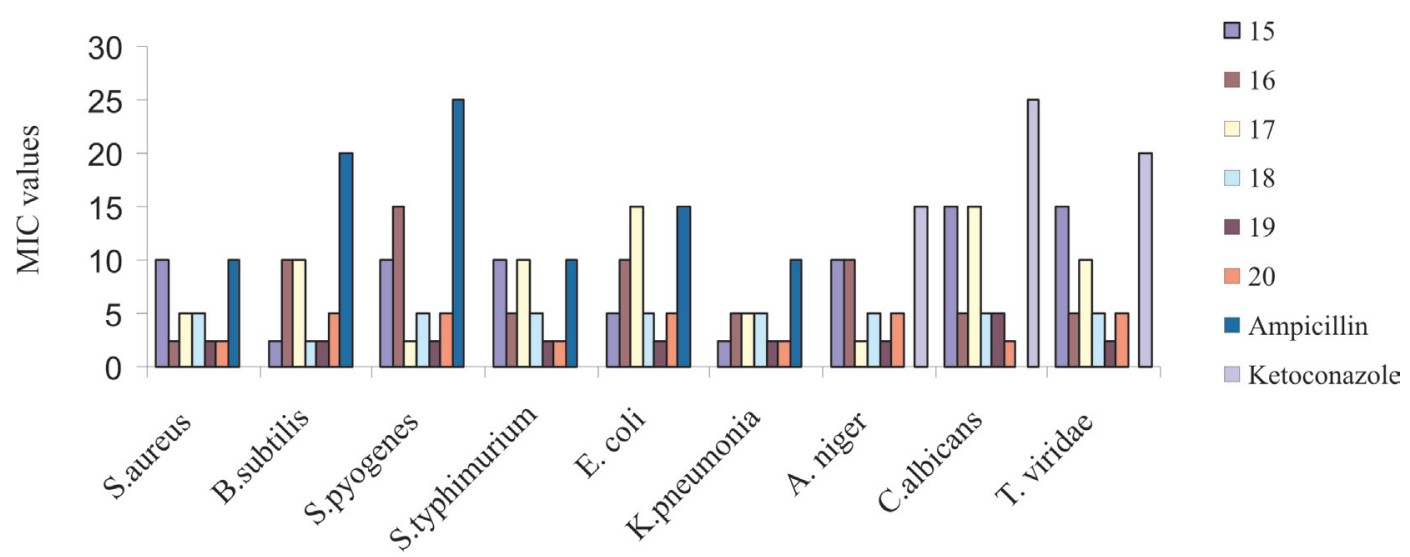

Bacteria and Fungi

Figure 1. Comparison of MIC values (in $\mu \mathrm{g} \mathrm{mL}^{-1}$ ) of quinazolines and standard drugs against different bacteria and fungi.

\section{Experimental}

All solvents used were of analytical grade. TLC analysis was done using precoated silica gel plates and visualization was done using iodine vapors. Micro analytical $(\mathrm{C}, \mathrm{N}, \mathrm{H})$ data was obtained by using a Perkin-Elmer $2400 \mathrm{CHN}$ elemental analyzer. The IR spectra were recorded in $\mathrm{KBr}$ pellets on Perkin- Elmer-283 spectrophotometer. ${ }^{1} \mathrm{H}$ NMR spectra were acquired at $400 \mathrm{MHz}$, and ${ }^{13} \mathrm{C}$ NMR at 67.93 $\mathrm{MHz}$ on a Bruker NMR spectrometer (Bruker Bioscience, 
USA). FAB mass spectra were recorded on a FinniganMAT 1020 instrument (Thermo Electron Corporation, Bremen, Germany). An ion trap mass spectrometer (Agilent Series LC/MSD Trap SL) equipped with an electrospray ionization (ESI) source was used for MS analyses (Agilent, Palo Alto, CA, USA). Microorganisms like Staphylococcus aureus (ATCC 25923), Bacillus subtilis (ATCC 9372), Streptococcus pyogenes (ATCC 19615) (Gram positive) and Salmonella typhimurium (ATCC 14028), Escherichia coli (ATCC 25922), Klebsiella pneumonia (ATCC 3882) (Gram negative) bacterial strains and Aspergillus niger (ATCC 16404), Candida albicans (ATCC 10231) and Trichoderma viridae (IAM 5061) fungal strains were used in the present investigation.

\section{Preparation of 2-(2-aminophenyl)indzole $(\boldsymbol{A})$}

The precursor 2-(2-aminophenyl)indole (A) was obtained by the Fischer indole synthesis from phenylhydrazine hydrochloride and 2-amino acetophenone using a mixture of methane sulfonic acid and phosphorus pentoxide at $85{ }^{\circ} \mathrm{C}$. All the reactions were carried out according to the procedure described by Billimoria and Cava. $^{5}$

Procedure for preparation of mono-2-(2-arylideneamino phenyl) indoles (1-10)

To a solution of precursor 2-(2-aminophenyl)indole (A, $0.416 \mathrm{~g}, 2 \mathrm{mmol}$ for $\mathbf{1 - 8}$ and $0.832 \mathrm{~g}, 4 \mathrm{mmol}$ for 9-10) in $20-40 \mathrm{~mL}$ of ethanol, $2 \mathrm{mmol}$ of $\mathrm{Ar}-\mathrm{CHO} /$ $\mathrm{CHO}-\mathrm{Ar}-\mathrm{CHO}$ and few drops of acetic acid was added with vigorous stirring. The reaction mixture was then refluxed for $3 \mathrm{~h}$. After cooling, the deposited solid product was collected by filtration and recrystalized from an ethanol/ dichloromethane-methanol mixture.

Procedure for preparation of 6-arylindolo[1,2-c] quinazolines (11-20)

The final compounds mono, bis-indolo[1,2-c] quinazolines (11-20 ) were prepared from intermediate azomethines (1-10) through oxidative cyclisation method. Powdered potassium permanganate ( 1.5 equiv.) was added to a solution of the azomethyne compound (11-20) in $50-75 \mathrm{~mL}$ of acetone. The reaction mixture was refluxed under heat $\left(40-60^{\circ} \mathrm{C}\right)$ for $30 \mathrm{~min}$. It was then filtered hot, and an equal volume of hot water added to the filtrate. The final products, 6-substituted indolo[1,2-c]quinazolines (11-20) rapidly separated, and was collected by filtration and recrystalized from dimethylformamide/ethanol.
N-benzylidene-2-(1H-indol-2-yl)benzenamine (1)

Yield 78\%; mp 196-198 ${ }^{\circ} \mathrm{C}$; IR (KBr) $v_{\max } / \mathrm{cm}^{-1}: 3400$, $1650,1595,1570,1128 ;{ }^{1} \mathrm{HNMR}\left(400 \mathrm{MHz}, \mathrm{CDCl}_{3}\right) \delta$ in ppm 6.73 (s, 1H, Ar), 6.95-7.18 (m, 3H, Ar), 7.23-7.65 (m, 10H, Ar), $8.10(\mathrm{~s}, 1 \mathrm{H}, \mathrm{CH}=\mathrm{N}), 8.29(\mathrm{~s}, 1 \mathrm{H},-\mathrm{NH}) ;{ }^{13} \mathrm{C}$ NMR $(67.93$ $\left.\mathrm{MHz}, \mathrm{CDCl}_{3}\right) \delta 114.4,118.6,121.5,123.6,126.7,130.2$, 131.5, 132.4, 136.2, 140.1, 142.5, 143.6, 146.5, 165.3 (21C, Ar-C); Anal. Found: C, 85.15; H, 5.51; N, 9.46\%. Calc. for $\mathrm{C}_{21} \mathrm{H}_{16} \mathrm{~N}_{2}: \mathrm{C}, 85.11 ; \mathrm{H}, 5.44 ; \mathrm{N}, 9.45 \%$. MS: [M] ${ }^{+}$at $\mathrm{m} / \mathrm{z} 296$.

2-(1H-indol-2-yl)-N-(naphthalen-2-ylmethylene) benzenamine (2)

Yield 75\%; mp 222-224 ${ }^{\circ} \mathrm{C}$; IR (KBr) $v_{\max } / \mathrm{cm}^{-1}: 3398$, $1641,1605,1575,1130 ;{ }^{1} \mathrm{H}$ NMR $\left(400 \mathrm{MHz}, \mathrm{CDCl}_{3}\right) \delta$ in ppm 6.71 (s, 1H, Ar), 6.90-7.11 (m, 2H, Ar), 7.25 -7.64 (m, 9H, Ar), $7.75-7.94(\mathrm{~m}, 4 \mathrm{H}, \mathrm{Ar}), 8.16(\mathrm{~s}, 1 \mathrm{H}, \mathrm{CH}=\mathrm{N})$, $8.35(\mathrm{~s}, 1 \mathrm{H},-\mathrm{NH}) ;{ }^{13} \mathrm{C} \mathrm{NMR}\left(67.93 \mathrm{MHz}, \mathrm{CDCl}_{3}\right) \delta 113.9$, $117.9,121.5,123.2,126.6,130.2,131.9,132.5,135.3$, 140.8, 142,2, 145.6, 148.5, 164.9 (25C, Ar-C); Anal. Found: C, 86.70; H, 5.22; N, 8.13\%. Calc. for $\mathrm{C}_{25} \mathrm{H}_{18} \mathrm{~N}_{2}$ : C, 86.68; $\mathrm{H}, 5.24 ; \mathrm{N}, 8.09 \%$. MS: $[\mathrm{M}]^{+}$at $\mathrm{m} / \mathrm{z} 346$.

2-(1H-indol-2-yl)-N-((6-methoxynaphthalen-2-yl) methylene)benzenamine (3)

Yield 79\%; mp 201-203 ${ }^{\circ} \mathrm{C}$; IR (KBr) $v_{\max } / \mathrm{cm}^{-1}: 3405$, 1637, 1605, 1588, 1130, 1038, 850; ${ }^{1} \mathrm{H}$ NMR (400 MHz, $\left.\mathrm{CDCl}_{3}\right) \delta$ in ppm 3.90 (s, 3H, OCH3), $6.72(\mathrm{~s}, 1 \mathrm{H}, \mathrm{Ar})$, 6.92-7.10 (m, 3H, Ar), 7.25-7.60(m, 9H, Ar), 7.73-7.82 (m, $2 \mathrm{H}, \mathrm{Ar}), 8.15(\mathrm{~s}, 1 \mathrm{H}, \mathrm{CH}=\mathrm{N}), 8.29(\mathrm{~s}, 1 \mathrm{H},-\mathrm{NH}) ;{ }^{13} \mathrm{C} \mathrm{NMR}$ $\left(67.93 \mathrm{MHz}, \mathrm{CDCl}_{3}\right) \delta 56.2,\left(1 \mathrm{C},-\mathrm{OCH}_{3}\right), 113.8,119.5$, 120.7, 123.6, 127.1, 130.2, 131.5, 132.3, 141.7, 142,2, 147.5, 151.5, 153.7, 166.9 (25C, Ar-C); Anal. Found: C, 83.01; H, 5.38; N, 7.43\%. Calc. for $\mathrm{C}_{26} \mathrm{H}_{20} \mathrm{~N}_{2} \mathrm{O}: \mathrm{C}, 82.95$; H, 5.35; N, 7.44\%. MS: $[\mathrm{M}]^{+}$at $m / z, 376$.

\section{2-(1H-indol-2-yl)-N-((1-nitronaphthalen-2-yl)methylene)} benzenamine (4)

Yield 81\%; mp 231-233 ${ }^{\circ} \mathrm{C}$; IR (KBr) $v_{\max } / \mathrm{cm}^{-1}$ : $3395,1638,1608,1589,1524,1346,1126,850 ;{ }^{1} \mathrm{H}$ NMR $\left(400 \mathrm{MHz}, \mathrm{CDCl}_{3}\right) \delta$ in ppm 6.71 (s, 1H, Ar), 6.90-7.12 (m, 2H, Ar), 7.25-7.68(m, 8H, Ar), 7.93-8.02 (m, 2H, Ar), 8.16 (s, $1 \mathrm{H}, \mathrm{CH}=\mathrm{N}), 8.23-8.25$ (m, 2H, Ar), 8.59 (s, $1 \mathrm{H}$, $-\mathrm{NH}) ;{ }^{13} \mathrm{C} \mathrm{NMR}\left(67.93 \mathrm{MHz}, \mathrm{CDCl}_{3}\right) \delta 114.2,117.5$, 119.0, 122.5, 125.2, 126.8, 132.3, 136.8, 142.1, 143.6, 147.8, 154.1, 167.2 (25C, Ar-C); Anal. Found: C, 76.80; $\mathrm{H}, 4.56 ; \mathrm{N}, 10.78 \%$. Calc. for $\mathrm{C}_{25} \mathrm{H}_{17} \mathrm{~N}_{3} \mathrm{O}_{2}: \mathrm{C}, 76.71 ; \mathrm{H}$, 4.38; N, 10.74\%. MS: $[\mathrm{M}]^{+}$at $\mathrm{m} / \mathrm{z} 391$.

2-(1H-indol-2-yl)- $N$-(pyridin-2-ylmethylene) benzenamine (5)

Yield 78\%; mp 185-187 ${ }^{\circ} \mathrm{C}$; IR (KBr) $v_{\max } / \mathrm{cm}^{-1}: 3400$, $1628,1605,1585,1109 ;{ }^{1} \mathrm{H} \mathrm{NMR}\left(400 \mathrm{MHz}, \mathrm{CDCl}_{3}\right) \delta$ in 
ppm 6.74 (s, 1H, Ar), 6.92-7.11 (m, 3H, Ar), 7.28-7.65 (m, $8 \mathrm{H}, \mathrm{Ar}), 8.18(\mathrm{~s}, 1 \mathrm{H}, \mathrm{CH}=\mathrm{N}), 8.32(\mathrm{~s}, 1 \mathrm{H},-\mathrm{NH}), 8.58(\mathrm{~m}$, $1 \mathrm{H}, \mathrm{Ar}) ;{ }^{13} \mathrm{C}$ NMR $\left(67.93 \mathrm{MHz}, \mathrm{CDCl}_{3}\right) \delta 114.3,118.1$, $122.5,123.6,126.5,130.5,131.7,132.9,136.2,141.5$, 142,3, 143.4, 146.7, 148.1, 155.8, 165.9 (20C, Ar-C); Anal. Found: C, 80.87; H, 5.09; N, 14.15\%. Calc. for $\mathrm{C}_{20} \mathrm{H}_{15} \mathrm{~N}_{3}$ : C, 80.78; H, 5.08; N, 14.13\%. MS: [M] ${ }^{+}$at $m / z 297$.

$N$-((1H-pyrrol-2-yl)methylene $)-2-(1 \mathrm{H}$-indol-2-yl) benzenamine $(\boldsymbol{6})$

Yield 75\%; mp 205-207 ${ }^{\circ} \mathrm{C}$; IR (KBr) $v_{\max } / \mathrm{cm}^{-1}: 3395$, 3215, 1638, 1606, 1578, 1132; ${ }^{1} \mathrm{H} \mathrm{NMR}\left(400 \mathrm{MHz}, \mathrm{CDCl}_{3}\right.$ ) $\delta$ in ppm $6.70(\mathrm{~s}, 1 \mathrm{H}, \mathrm{Ar}), 6.12-7.10(\mathrm{~m}, 5 \mathrm{H}, \mathrm{Ar}), 7.22-7.61$ (m, 6H, Ar), $8.15(\mathrm{~s}, 1 \mathrm{H}, \mathrm{CH}=\mathrm{N}), 8.56(\mathrm{~s}, 1 \mathrm{H},-\mathrm{NH}), 8.85(\mathrm{~s}$, $1 \mathrm{H}$, pyrrolyl NH); ${ }^{13} \mathrm{C}$ NMR $\left(67.93 \mathrm{MHz}, \mathrm{CDCl}_{3}\right) \delta 113.5$, 114.2, 118.7, 120.9, 123.2, 126.6, 130.4, 131.7, 133.1, 136.7, 140.3, 141.6, 145.7, 146.2, 150.9 (19C, Ar-C); Anal. Found: C, 80.01; H, 5.35; N, 14.82\%. Calc. for $\mathrm{C}_{19} \mathrm{H}_{15} \mathrm{~N}_{3}$ : C, 79.98; H, 5.30; N, 14.73\%. MS: [M] ${ }^{+}$at $m / z 285$.

$\mathrm{N}$-(furan-2-ylmethylene)-2-(1H-indol-2-yl)benzenamine (7)

Yield 80\%; mp 215-217 ${ }^{\circ} \mathrm{C}$; IR (KBr) $v_{\text {max }} / \mathrm{cm}^{-1}: 3398$, 1636, 1608, 1583, 1130; ${ }^{1} \mathrm{H}$ NMR $\left(400 \mathrm{MHz}, \mathrm{CDCl}_{3}\right) \delta$ in ppm 6.45 (s, 1H, Ar), 6.72 (s, 1H, Ar), 6.80-7.11 (m, 3H, Ar), 7.29-7.61 (m, 7H, Ar), $8.14(\mathrm{~s}, 1 \mathrm{H}, \mathrm{CH}=\mathrm{N}), 8.28(\mathrm{~s}$, $1 \mathrm{H},-\mathrm{NH}) ;{ }^{13} \mathrm{C}$ NMR $\left(67.93 \mathrm{MHz}, \mathrm{CDCl}_{3}\right) \delta 112.4,113.9$, $114.4,120.8,122.9,123.4,126.1,130.7,131.2,132.5$, 140.6, 142.8, 143.4 146.2, 155.6 (19C, Ar-C); Anal. Found: C, 79.72; H, 4.99; N, 9.86\%. Calc. for $\mathrm{C}_{19} \mathrm{H}_{14} \mathrm{~N}_{2} \mathrm{O}$ : C, 79.70; H, 4.93; N, 9.78\%. MS: [M] ${ }^{+}$at $m / z, 286$.

\section{2-(1H-indol-2-yl)-N-(thiophen-2-ylmethylene)} benzenamine ( 8 )

Yield 76\%; mp 221-223 ${ }^{\circ} \mathrm{C}$; IR (KBr) $v_{\max } / \mathrm{cm}^{-1}: 3395$, 1638, 1610, 1586, 1132, 698; ${ }^{1} \mathrm{H}$ NMR (400MHz, $\left.\mathrm{CDCl}_{3}\right)$ $\delta$ in ppm $6.73(\mathrm{~s}, 1 \mathrm{H}, \mathrm{Ar}), 6.92-7.14(\mathrm{~m}, 4 \mathrm{H}, \mathrm{Ar}), 7.28-7.62$ $(\mathrm{m}, 7 \mathrm{H}, \mathrm{Ar}), 8.16(\mathrm{~s}, 1 \mathrm{H}, \mathrm{CH}=\mathrm{N}), 8.29(\mathrm{~s}, 1 \mathrm{H},-\mathrm{NH}) ;{ }^{13} \mathrm{C}$ NMR $\left(67.93 \mathrm{MHz}, \mathrm{CDCl}_{3}\right) \delta 114.5,118.8,120.4,123.2$, $126.8,130.2,131.5,132.8,133.3,140.2,143.6,146.4$, 147.8, 148.9 (19C, Ar-C); Anal. Found: C, 75.52; H, 4.69; N, 9.28\%. Calc. for $\mathrm{C}_{19} \mathrm{H}_{14} \mathrm{~N}_{2} \mathrm{~S}: \mathrm{C}, 75.47 ; \mathrm{H}, 4.67 ; \mathrm{N}, 9.26 \%$. MS: $[\mathrm{M}]^{+}$at $m / z, 302$.

$N-((5-((2-(1 H-i n d o l-2-y l) p h e n y l i m i n o) m e t h y l) t h i o p h e n-2-$ yl)methylene)-2-(1H-indol-2-yl)benzenamine (9)

Yield 78\%; mp 245-247 ${ }^{\circ} \mathrm{C}$; IR (KBr) $v_{\max } / \mathrm{cm}^{-1}: 3400$, 1625, 1602, 1586, 1128, 696; ${ }^{1} \mathrm{H}$ NMR (400 MHz, $\mathrm{CDCl}_{3}$ ) $\delta$ in ppm 6.74 (s, 2H, Ar), 6.91-7.12 (m, 4H, Ar), 7.21 (s, $2 \mathrm{H}, \mathrm{Ar}), 7.31-7.62$ (m, 12H, Ar), 8.14 (s, 2H, CH=N), 8.32 (s, 2H, -NH); ${ }^{13} \mathrm{C}$ NMR $\left(67.93 \mathrm{MHz}, \mathrm{CDCl}_{3}\right) \delta 113.8$,
$114.2,120.3,123.5,125.6,127.1,128.9,130.2,131.6$, $132.8,140.9,142.6,144.3,145.7,146.2,146.9,152.4$ (34C, Ar-C); Anal. Found: C, 78.46; H, 4.72; N, 10.78\%. Calc. for $\mathrm{C}_{34} \mathrm{H}_{24} \mathrm{~N}_{4} \mathrm{~S}$ : C, 78.44; H, 4.65; N, 10.76\%. MS: $[\mathrm{M}]^{+}$at $m / z 520$.

$N-((6-((2-(1 H-i n d o l-2-y l) p h e n y l i m i n o) m e t h y l) p y r i d i n-2-y l)$ methylene)-2-(1H-indol-2-yl)benzenamine (10)

Yield 78\%; mp 238-240 ${ }^{\circ} \mathrm{C}$; IR (KBr) $v_{\text {max }} / \mathrm{cm}^{-1}: 3405$, $1645,1610,1585,1132 ;{ }^{1} \mathrm{H}$ NMR $\left(400 \mathrm{MHz}, \mathrm{CDCl}_{3}\right) \delta$ in ppm 6.72 (s, 2H, Ar), 6.90-7.11 (m, 4H, Ar), 7.21-7.62 (m, $14 \mathrm{H}, \mathrm{Ar}), 7.82(\mathrm{~m}, 1 \mathrm{H}, \mathrm{Ar}), 8.16(\mathrm{~s}, 2 \mathrm{H}, \mathrm{CH}=\mathrm{N}), 8.38(\mathrm{~s}, 2 \mathrm{H}$, $-\mathrm{NH}) ;{ }^{13} \mathrm{C} \mathrm{NMR}\left(67.93 \mathrm{MHz}, \mathrm{CDCl}_{3}\right) \delta 114.4,114.7,121.8$, 123.2, 125.7, 127.9, 128.1,130.6, 131.3, 132.7, 141.3, 142.3, 144.8, 145.8, 146.1 155.5, 167.9 (35 C, Ar-C) Anal. Found: C, 81.57; H, 4.92; N, 13.63\%. Calc. for $\mathrm{C}_{35} \mathrm{H}_{25} \mathrm{~N}_{5}: \mathrm{C}, 81.53$; $\mathrm{H}, 4.89 ; \mathrm{N}, 13.58 \%$. MS: $[\mathrm{M}]^{+}$at $m / z 515$.

\section{6-phenylindolo[1,2-c]quinazoline (11)}

Yield $81 \%$; mp 210-212 ${ }^{\circ} \mathrm{C}$; IR (KBr) $v_{\max } / \mathrm{cm}^{-1}: 1620$, $1581,1535,1457,1378,775,741,733 ;{ }^{1} \mathrm{H}$ NMR $(400 \mathrm{MHz}$, DMSO-d $\left.{ }_{6}\right) \delta$ in ppm 7.01-7.12 (m, 3H, Ar), 7.25-7.51 (m, $4 \mathrm{H}, \mathrm{Ar}), 7.61-7.88$ (m, 7H, Ar); ${ }^{13} \mathrm{C}$ NMR $(67.93 \mathrm{MHz}$, DMSO- $\left.d_{6}\right) \delta 113.2,119.1,120.2,122.7,124.4,126.3$, 127.9, 129.1, 130.5, 131.2, 132.4, 133.8, 145.4, 146.5, 152.8 (21 C, Ar-C); Anal. Found: C, 85.73; H, 4.80; N, 9.56\%. Calc. for $\mathrm{C}_{21} \mathrm{H}_{14} \mathrm{~N}_{2}: \mathrm{C}, 85.69 ; \mathrm{H}, 4.79 ; \mathrm{N}, 9.52 \%$. MS: [M] ${ }^{+}$at $m / z 294$.

\section{6-(2-naphthyl)indolo[1,2-c]quinazoline (12)}

Yield 80\%; mp 235-237 ${ }^{\circ} \mathrm{C}$; IR (KBr) $v_{\max } / \mathrm{cm}^{-1}: 1625$, 1585, 1530, 1459, 1385, 773, 741, 732; ${ }^{1} \mathrm{H}$ NMR $(400 \mathrm{MHz}$, DMSO- $\left.d_{6}\right) \delta$ in ppm $7.02(\mathrm{~m}, 1 \mathrm{H}, \mathrm{Ar}), 7.21-7.56(\mathrm{~m}, 6 \mathrm{H}$, Ar), 7.61-7.72 (m, 3H, Ar), 7.80-8.03 (m, 5H, Ar), 8.32 (s, $1 \mathrm{H}, \mathrm{Ar}) ;{ }^{13} \mathrm{C}$ NMR $\left(67.93 \mathrm{MHz}, \mathrm{DMSO}-d_{6}\right) \delta 112.3,120.3$, 121.4, 122.2, 123.9, 125.6, 129.1, 130.3, 132.5, 141.4, 145.5, 151.2, 156.4, 164.3 (25 C, Ar-C); Anal. Found: C, 87.20; H, 4.71; N, 8.15\%. Calc. for $\mathrm{C}_{25} \mathrm{H}_{16} \mathrm{~N}_{2}: \mathrm{C}, 87.18 ; \mathrm{H}$, 4.68; N, 8.13\%. MS: $[\mathrm{M}]^{+}$at $m / z, 344$.

\section{6-(6-methoxy-2-naphthyl)indolo[1,2-c]quinazoline (13)}

Yield 78\%; mp 218-220 ${ }^{\circ} \mathrm{C}$; IR (KBr) $v_{\max } / \mathrm{cm}^{-1}: 1628$, 1585, 1540, 1458, 1375, 1042, 775, 743, 731; ${ }^{1} \mathrm{H}$ NMR $\left(400 \mathrm{MHz}, \mathrm{DMSO}-d_{6}\right) \delta$ in ppm 3.90 (s, $\left.3 \mathrm{H}, \mathrm{OCH} 3\right), 7.01-$ $7.06(\mathrm{~m}, 2 \mathrm{H}, \mathrm{Ar}), 7.25-7.52(\mathrm{~m}, 5 \mathrm{H}, \mathrm{Ar}), 7.60-8.13(\mathrm{~m}, 7 \mathrm{H}$, Ar), 8.36 (s, $1 \mathrm{H}, \mathrm{Ar}) ;{ }^{13} \mathrm{C}$ NMR (67.93 MHz, DMSO- $\left.d_{6}\right)$ $\delta 56.4,(1 \mathrm{C},-\mathrm{OCH} 3), 113.2,119.8,121.2,122.3,124.2$, $125.8,129.3,130.4,131.7,132.6,142.1,145.3,150.2$, 155.9, 164.9 (25C, Ar-C); Anal. Found: C, 83.42; H, 4.89; N, 7.50\%. Calc. for $\mathrm{C}_{26} \mathrm{H}_{18} \mathrm{~N}_{2} \mathrm{O}: \mathrm{C}, 83.40 ; \mathrm{H}, 4.85 ; \mathrm{N}$, 7.48\%. MS: $[\mathrm{M}]^{+}$at $m / z 374$. 
6-(1-nitro-2-naphthyl)indolo[1,2-c]quinazoline (14)

Yield 78\%; mp 225-227 ${ }^{\circ} \mathrm{C}$; IR (KBr) $v_{\max } / \mathrm{cm}^{-1}: 1635$, 1585, 1528, 1460, 1386, 852, 775, 741, 733; ${ }^{1} \mathrm{H}$ NMR $\left(400 \mathrm{MHz}\right.$, DMSO-d $\left.{ }_{6}\right) \delta$ in ppm $7.04(\mathrm{~m}, 1 \mathrm{H}, \mathrm{Ar}), 7.28-7.42$ (m, 3H, Ar), 7.58-7.73 (m, 5H, Ar), 7.85-8.12 (m, 4H, Ar), 8.28-8.40 (m, 2H, Ar); ${ }^{13} \mathrm{C}$ NMR $\left(67.93 \mathrm{MHz}\right.$, DMSO- $\left.d_{6}\right)$ $\delta$ 112.6, 119.7, 121.2, 123.5, 124.2, 125.5, 129.7, 130.3, 131.8, 141.9, 145.8, 152.4, 164.8 (25 C, Ar-C); Anal. Found: C, 77.15; $\mathrm{H}, 3.90 ; \mathrm{N}, 10.80 \%$. Calc. for $\mathrm{C}_{25} \mathrm{H}_{15} \mathrm{~N}_{3} \mathrm{O}_{2}$ : C, $77.11 ; \mathrm{H}, 3.88 ; \mathrm{N}, 10.79 \%$. MS: $[\mathrm{M}]^{+}$at $\mathrm{m} / z 389$.

\section{6-(2-pyridyl)indolo[1,2-c]quinazoline (15)}

Yield 76\%; mp 209-211 ${ }^{\circ} \mathrm{C}$; IR (KBr) $v_{\max } / \mathrm{cm}^{-1}: 1625$, $1608,1535,1448,1380,773,740,733 ;{ }^{1} \mathrm{H}$ NMR $(400 \mathrm{MHz}$, DMSO-d $\left._{6}\right) \delta$ in ppm 7.02-7.05 (m, 2H, Ar), 7.21-7.72 (m, $8 \mathrm{H}, \mathrm{Ar}), 7.82-7.86$ (m, 2H, Ar), 8.69 (m, 1H, Ar); ${ }^{13} \mathrm{C} \mathrm{NMR}$ $\left(67.93 \mathrm{MHz}, \mathrm{DMSO}-d_{6}\right) \delta 113.1,120.2,121.5,122.9$, $125.1,126.5,129.2,130.6,131.8,133.2,138.5,142.3$, 145.7, 146.2, 151.3 153.5, 154.2 (20 C, Ar-C); Anal. Found: C, 81.37; H, 4.48; N, 14.24\%. Calc. for $\mathrm{C}_{20} \mathrm{H}_{13} \mathrm{~N}_{3}$ : C, 81.34; H, 4.44; N, 14.23\%. MS: [M] ${ }^{+}$at $m / z 295$.

\section{6-(1H-2-pyrrolyl)indolo[1,2-c]quinazoline (16)}

Yield 79\%; mp 193-195 ${ }^{\circ} \mathrm{C}$; IR (KBr) $v_{\max } / \mathrm{cm}^{-1}: 3215$, 1638, 1610, 1581, 1469, 1388, 772, 743, 736; ' ${ }^{1} \mathrm{H}$ NMR $\left(400 \mathrm{MHz}\right.$, DMSO-d $\mathrm{d}_{6} \delta$ in ppm $5.62(\mathrm{~m}, 1 \mathrm{H}, \mathrm{Ar}), 6.35$ (m, 1H, Ar), 7.01-7.05 (m, 2H, Ar), 7.23-7.85 (m, 8H, Ar), 10.6 (s, $1 \mathrm{H}$, pyrrolyl $\mathrm{NH}) ; ;{ }^{13} \mathrm{C}$ NMR $\left(67.93 \mathrm{MHz}\right.$, DMSO- $\left.d_{6}\right)$ $\delta$ 112.6, 113.9, 119.5, 120.7, 122.5, 124.5, 125.3, 127.1, 129.6, 130.4, 132.4, 141.7, 143.4, 145.3, 146.2, 148.3, 150.1 (19C, Ar-C); Anal. Found: C, 80.56; H, 4.68; N, $14.85 \%$. Calc. for $\mathrm{C}_{19} \mathrm{H}_{13} \mathrm{~N}_{3}$ : C, 80.54; H, 4.62; N, 14.83\%. MS: [M] ${ }^{+}$at $m / z 283$.

\section{6-(2-furyl)indolo[1,2-c]quinazoline (17)}

Yield 75\%; mp 224-226 ${ }^{\circ} \mathrm{C}$; IR (KBr) $v_{\max } / \mathrm{cm}^{-1}: 1640$, 1608, 1579, 1470, 1388, 771, 742, 736; ${ }^{1} \mathrm{H}$ NMR $(400 \mathrm{MHz}$, DMSO- $\left.\mathrm{d}_{6}\right) \delta$ in ppm 6.25-6.43 (m, 2H, Ar), $7.04(\mathrm{~m}$, $1 \mathrm{H}, \mathrm{Ar}), 7.25-7.83$ (m, 9H, Ar); ${ }^{13} \mathrm{C}$ NMR $(67.93 \mathrm{MHz}$, DMSO- $\left.d_{6}\right) \delta 112.2,113.5,120.8,121.3,122.9,124.4$, $126.5,126.9,130.5,131.3,132.5,138.1,142.9,145.4$, 146.5, 147.7, 149.5 (19C, Ar-C); Anal. Found: C, 80.30; $\mathrm{H}, 4.29 ; \mathrm{N}, 9.86 \%$. Calc. for $\mathrm{C}_{19} \mathrm{H}_{12} \mathrm{~N}_{2} \mathrm{O}$ : C, 80.27; H, 4.25; N, 9.85\%. MS: [M] ${ }^{+}$at $m / z 284$.

\section{6-(2-thienyl)indolo[1,2-c]quinazoline (18)}

Yield 76\%; mp 236-238 ${ }^{\circ} \mathrm{C}$; IR (KBr) $v_{\text {max }} / \mathrm{cm}^{-1}: 1638$, 1609, 1582, 1465, 1388, 772, 743, 748, 692; ${ }^{1} \mathrm{H}$ NMR $\left(400 \mathrm{MHz}, \mathrm{DMSO}-d_{6}\right) \delta$ in ppm 6.45 (s, $\left.1 \mathrm{H}, \mathrm{Ar}\right), 7.01-7.05$ (m, 2H, Ar), 7.28-7.85 (m, 9H, Ar); ${ }^{13} \mathrm{C}$ NMR $(67.93 \mathrm{MHz}$, DMSO- $\left.d_{6}\right) \delta 112.2,119.5,120.8,121.5,123.2,124.1$,
125.5, 126.4, 130.3, 131.7, 132.7, 136.9, 142.7, 145.4, 146.7, 148.2, 149.7 (19C, Ar-C); Anal. Found: C, 76.01; $\mathrm{H}, 4.02 ; \mathrm{N}, 9.35 \%$. Calc. for $\mathrm{C}_{19} \mathrm{H}_{12} \mathrm{~N}_{2} \mathrm{~S}: \mathrm{C}, 75.97 ; \mathrm{H}, 4.03$; N, 9.33\%. MS: [M] ${ }^{+}$at $m / z, 300$.

6-(5-indolo[1,2-c]quinazolin-6-yl-2-thienyl)indolo[1,2-c] quinazoline (19)

Yield 79\%; mp 250-252 ${ }^{\circ} \mathrm{C}$; IR (KBr) $v_{\max } / \mathrm{cm}^{-1}: 1640$, $1605,1458,1382,1135,774,740,732,695 ;{ }^{1} \mathrm{H}$ NMR (400 MHz, DMSO- $d_{6}$ ) $\delta$ in ppm 6.68 (s, 2H, Ar), 7.02-7.07 (m, 2H, Ar), 7.25-7.86 (m, 16H, Ar); ${ }^{13} \mathrm{C}$ NMR (67.93 MHz, DMSO- $\left.d_{6}\right) \delta 110.7,111.4,112.6,119.2,120.5,121.8$, $122.8,123.8,126.4,129.2,130.6,132.3,133.7,138.4$, 140.7, 143.4, 145.6, 147.8, 150.2, 152.8 (34C, Ar-C); Anal. Found: C, 79.06; H, 3.98; N, 10.85\%. Calc. for $\mathrm{C}_{34} \mathrm{H}_{20} \mathrm{~N}_{4} \mathrm{~S}$ : C, 79.05; H, 3.90; N, 10.84\%. MS: [M] ${ }^{+}$at $m / z 516$.

6-(6-indolo[1,2-c]quinazolin-6-yl-2-pyridyl)indolo[1,2-c] quinazoline (20)

Yield $72 \%$; mp 255-256 ${ }^{\circ} \mathrm{C}$; IR (KBr) $v_{\max } / \mathrm{cm}^{-1}: 1628$, 1606, 1586, 1385, 1128, 745, 736, 730; ${ }^{\mathrm{H}} \mathrm{H}$ NMR $(400 \mathrm{MHz}$, DMSO- $d_{6}$ ) $\delta$ in ppm 7.02-7.07 (m, 4H, Ar), 7.25-7.82 (m, $16 \mathrm{H}, \mathrm{Ar}), 7.92$ (t, $1 \mathrm{H}, \mathrm{Ar}, J 7.8 \mathrm{~Hz}) ;{ }^{13} \mathrm{C}$ NMR $(67.93 \mathrm{MHz}$, DMSO-d $\left.{ }_{6}\right) \delta 112.6,113.7,120.8,121.3,122.4,123.6$, 124.6, 126.5, 128.2, 131.7, 133.4, 135.8, 139.2, 140.3, 143.9, 145.6, 148.2, 152.2, 153.7, 155.9 (35C, Ar-C); Anal. Found: C, 82.16; H, 4.16; N, 13.72\%. Calc. for $\mathrm{C}_{35} \mathrm{H}_{21} \mathrm{~N}_{5}$ : C, $82.17 ; \mathrm{H}, 4.14 ; \mathrm{N}, 13.69 \%$. MS: [M] ${ }^{+}$at $m / z 511$.

\section{Supplementary Information}

Supplementary data are available free of charge at http:// jbcs.sbq.org.br, as PDF file.

\section{Acknowledgments}

The authors thank the University Grant Commission (UGC, F.No. 34-363/2008(SR)), New Delhi, India and National Science Council (NSC), Taiwan for financially supporting this research.

\section{References}

1. Conchon, E.; Aboab, B.; Golsteyn, R. M.; Cruzalegui, F.; Edmonds, T.; Leonce, S.; Pfeiffer, B.; Prudhomme, M.; Eur. J. Med. Chem. 2006, 41, 1470.

2. Via, L. D.; Gia, O.; Magno, S. M.; Settimo, A. D.; Primofiore, G.; Settimo, F. D.; Simorini, F.; Marini, A. M.; Eur. J. Med. Chem. 2002, 37, 475.

3. Lounasmaa, M.; Tolvanen, A.; Nat. Prod. Rep. 2000, 17, 175.

4. Toyota, M.; Ihara, M.; Nat. Prod. Rep. 1998, 15, 327. 
5. Billimoria, A. D.; Cava, M. P.; J. Org. Chem. 1994, 59, 6777.

6. Blackman, A.; Hambley, T. W.; Picker, R.; Taylor, W. C.; Thirasana, N.; Tetrahedron Lett. 1987, 28, 5561.

7. Bhati, S. K.; Kumar, A.; Eur. J. Med. Chem. 2008, 43, 2323.

8. Sonar, V. N.; Yazadan; Khadar, S.; Sreenivasulu, N.; Indian J. Heterocycl. Chem. 2001, 19, 299.

9. Archana, P.; Rani, K.; Bajaj, V. K.; Srivastava, R.; Chandra Kumar, A.; Forsch, A.; Drug Res. 2003, 55, 301.

10. Wincent, E.; Shirani, H.; Bergman, J.; Rannug, U.; Janosik, T.; Bioorg. Med. Chem. 2009, 17, 1648.

11. Sinha, D.; Tiwari, A. K.; Singh, S.; Shukl, G..; Mishra, P.; Chandra, H.; Mishra, A. K.; Eur. J. Med. Chem. 2008, 43, 160.

12. Miert, S. V.; Hostyn, S.; Maes, B. U. M.; Cimanga, K.; Brun, R.; Kaiser, M.; Matyus, P.; Dommisse, R.; Lemiere, G.; Vlietinck, A.; Pieters, L.; J. Nat. Prod. 2005, 68, 674.

13. Bhattacharjee, A. K.; Hartell, M. G..; Nichols, D. A.; Hicks, R. P.; Stanton, B.; van Hamont, J. E.; Milhous, W. K.; Eur. J. Med. Chem. 2004, 39, 59.

14. Prudhomme, M.; Eur. J. Med. Chem. 2003, 38, 123.

15. He, L.; Chang, H.; Chou, T. C.; Savaraj, N.; Cheng, C. C.; Eur. J. Med. Chem. 2003, 38, 101.

16. Caballero, E.; Adeva, M.; Calderon, S.; Sahagun, H.; Tome, F.; Medarde, M.; Fernandez, J.; Lazaroc, M. L.; Ayuso, M. J.; Bioorg. Med. Chem. 2003, 11, 3413.

17. Moreau, P.; Sancelme, M.; Bailly, C.; Leonce, S.; Pierre, A.; Hickman, J.; Pfeiffer, B.; Prudhomme, M.; Eur. J. Med. Chem. 2001, 36, 887.

18. Zhu, X. Y.; Mardenborough, L. G..; Li, S.; Khan, A.; Zhang, W.; Fan, P.; Jacob, M.; Khan, S.; Walkerb, L.; Ablordeppeya, S. Y.; Bioorg. Med. Chem. 2007, 15, 686.

19. Chen, Y. L.; Hung, H. M.;. Lu, C. Mi; Li, K. C.; Tzeng, C. C.; Bioorg. Med. Chem. 2004, 12, 6539.

20. Scovill, J.; Blank, E.; Konnick, M.; Nenortas, E.; Shapiro, T.; Antimicrob. Agents Chemother. 2002, 46, 882.
21. Sharma, V. M.; Prasanna, P.; Seshu, K. V. A.; Renuka, B.; Laxman Rao, C. V.; Kumar, G.. S.; Narasimhulu, C. P.; Babu, P. A.; Puranik, R. C.; Subramanyam, D.; Venkateswarlu, A.; Rajagopal, S.; Kumar, K. B. S.; Rao, C. S.; Mamidi, N. V. S. R.; Deevi, D. S.; Ajaykumar, R.; Rajagopalan, R.; Bioorg. Med. Chem. Lett. 2002, 12, 2303.

22. Hong, C.; Firestone, G. L.; Bjeldanes, L. F.; Biochem. Pharmacol. 2002, 63, 1085.

23. Garbe, T. R.; Kobayashi, M.; Shimizu, N.; Takesue, N.; Ozawa, M.; Yukawa, H.; J. Nat. Prod. 2000, 63, 596.

24. Gurkok, G.; Altanlar, N.; Suzen, S.; Chemotherapy 2009, 55, 15.

25. Rohini, R.; Shanker, K.; Reddy, P. M.; Sekhar, V. C.; Ravinder, V.; Arch. Pharm. Chem. Life Sci. 2009, 342, 533.

26. Kiang, A. K.; Mann, F. G.; Prior, A. F.; Topham, A.; J. Chem. Soc. 1956, 1319.

27. Billimoria, A. D.; Cava, M. P.; Heterocycles 1996, 42, 453.

28. Frere, S.; Thiery, V.; Bailly, C.; Bessona, T.; Tetrahedron 2003, $59,773$.

29. Molina, P.; Alajarin, M.; Vidal, A.; Tetrahedron 1990, 46, 1063.

30. Talbi, H.; Humbert, B.; Billaud, D.; Synth. Met. 1997, 84, 875.

31. Sahu, S. K.; Azam, M. A.; Banerjee, M.; Acharrya, S.; Behera, C. C.; Si, S.; J. Braz. Chem. Soc. 2008, 19, 963.

32. Vostrova, L. N.; Voronina, T. A.; Karaseva, T. L.; Gernega, S. A.; Ivanov, É. I.; Kirichenko, A. M.; Totrova, M. Yu.; Pharm. Chem. J. 1986, 20, 404.

33. Jung, H. J.; Singh, N.; Jang, D. O.; Tetrahedron Lett. 2008, 49, 2960.

34. Reddy, P. M.; Ho, Y. P.; Shanker, K.; Rohini, R.; Ravinder, V.; Eur. J. Med. Chem. 2009, 44, 2621.

35. Rohini, R.; Shanker, K.; Reddy, P. M.; Ho, Y. P.; Ravinder, V.; Eur. J. Med. Chem. 2009, 44, 3330.

36. Rohini, R.; Shanker, K.; Reddy, P. M.; Ravinder, V.; J. Braz. Chem. Soc. 2010, 21, 49. 


\title{
Synthesis of Some New Mono, Bis-Indolo[1, 2-c]quinazolines: Evaluation of their Antimicrobial Studies
}

\author{
Rondla Rohini, ${ }^{a, c}$ P. Muralidhar Reddy, ${ }^{a, b}$ Kanne Shanker, ${ }^{a}$ \\ Anren $\mathrm{Hu}^{*, c}$ and Vadde Ravinder $*, a$ \\ ${ }^{a}$ Department of Chemistry, Kakatiya University, Warangal-506 009, A.P, India \\ ${ }^{b}$ Department of Chemistry, National Dong Hwa University, Hualien, Taiwan \\ ${ }^{c}$ Department of Laboratory Medicine and Biotechnology, Tzu Chi University, Hualien, Taiwan
}

\section{Antibacterial Activity}

Antibacterial testing was performed by cup plate method. Nutrient broth was prepared by dissolving peptone $(0.5 \%)$, yeast extract $(0.15 \%)$, beef extract $(0.15 \%)$, sodium chloride $(0.36 \%)$, and monopotassium phosphate $(0.13 \%)$ in distilled water $(100 \mathrm{~mL})$. The $\mathrm{pH}$ of the solution was adjusted to 7.2 by adding sodium hydroxide solution (4\%) and the resulting solution was autoclaved for $20 \mathrm{~min}$ at 15 psi. One day prior to the experiment, the cultures against Staphylococcus aureus, Bacillus subtilis, Streptococcus pyogenes,Salmonella typhimurium, Escherichia coli and Klebsiella pneumonia were inoculated in nutrient broth (inoculation medium) and incubated overnight at 37 ${ }^{\circ} \mathrm{C}$. Nutrient agar medium was prepared by dissolving peptone $(1 \%)$, yeast extract $(0.6 \%)$, beef extract $(0.5 \%)$, and sodium chloride $(0.5 \%)$ in distilled water. The $\mathrm{pH}$ of the solution was adjusted to 7.2 by adding $4 \%$ aqueous sodium hydroxide solution. Agar (2.4\%) was then added and the whole solution was autoclaved for $20 \mathrm{~min}$ at $15 \mathrm{psi}$. Preliminary screening for ten quinazolines was performed at fixed concentrations of $1000 \mu \mathrm{g} \mathrm{mL}-1$. Inoculation medium containing $24 \mathrm{~h}$ grown culture was added aseptically to the nutrient medium and mixed thoroughly to get the uniform distribution. This solution was poured ( $25 \mathrm{~mL}$ in each dish) into Petri dishes and then allowed to attain room temperature. Thereafter, six millimeter wide bores were made on the agar using a borer. The solutions of test samples were added into each of the bores using a sterile tip with micropipette. Ampicillin was used as the standard and DMSO as the solvent control. The test samples and the standard were tested at a concentration of
$1000 \mu \mathrm{g}$. The plates were allowed to stand for an hour in order to facilitate the diffusion of the drug solution. Then the plates were incubated at $37{ }^{\circ} \mathrm{C}$ for 24 hours. The zones of inhibition against all the microorganisms were measured in millimeters.

\section{Antifungal Activity}

The antifungal activity of quinazoline compounds were tested against the pathogenic fungi Aspergillus niger, Candida albicans, Trichoderma viridae by cup-plate method. Nutrient agar medium was prepared by the same method as explained under evaluation of antibacterial activity. One and half day prior to the experiment, the fungal cultures of Aspergillus niger, Candida albicans and Trichoderma viridae prepared in the inoculation medium were incubated at $37^{\circ} \mathrm{C}$ for $36 \mathrm{~h}$. The fungal medium was prepared by dissolving peptone $(0.5 \%)$, sodium chloride $(0.36 \%)$, monopotassium phosphate $(0.13 \%)$, and glucose $(2 \%)$ in distilled water $(100 \mathrm{~mL})$. The $\mathrm{pH}$ of the solution was adjusted to 7.2 by adding sodium hydroxide solution (4\%) and the resulting solution was autoclaved for $20 \mathrm{~min}$ at $15 \mathrm{psi}$. This was cooled to $45-50^{\circ} \mathrm{C}$ with gentle shaking. One and half day, grown cultures were added aseptically to this medium and mixed thoroughly to get uniform distribution. The solutions of the test samples and standard were evaluated for antifungal activity by cup-plate method at a concentration of $1000 \mu \mathrm{g}$. The zone of inhibition was measured in millimeter for the particular test sample with each organism at 48 hours interval. Ketoconazole was used as the standard.

*e-mail: anren@mail.tcu.edu.tw; ravichemku@ @rediffmail.com 


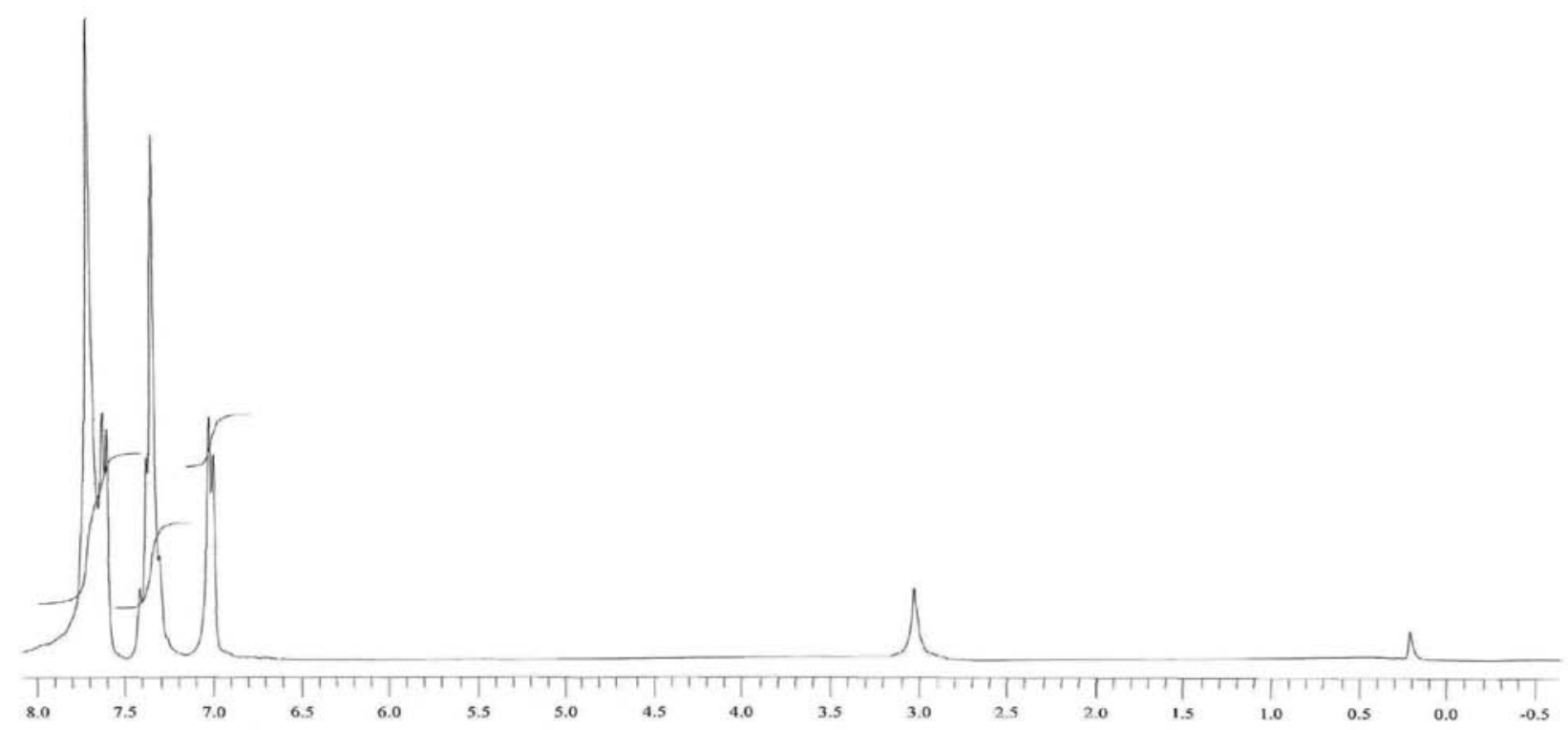

Figure S1. ${ }^{1} \mathrm{H}$ NMR spectrum of 6-phenyl indolo[1,2-c]quinazoline (11).

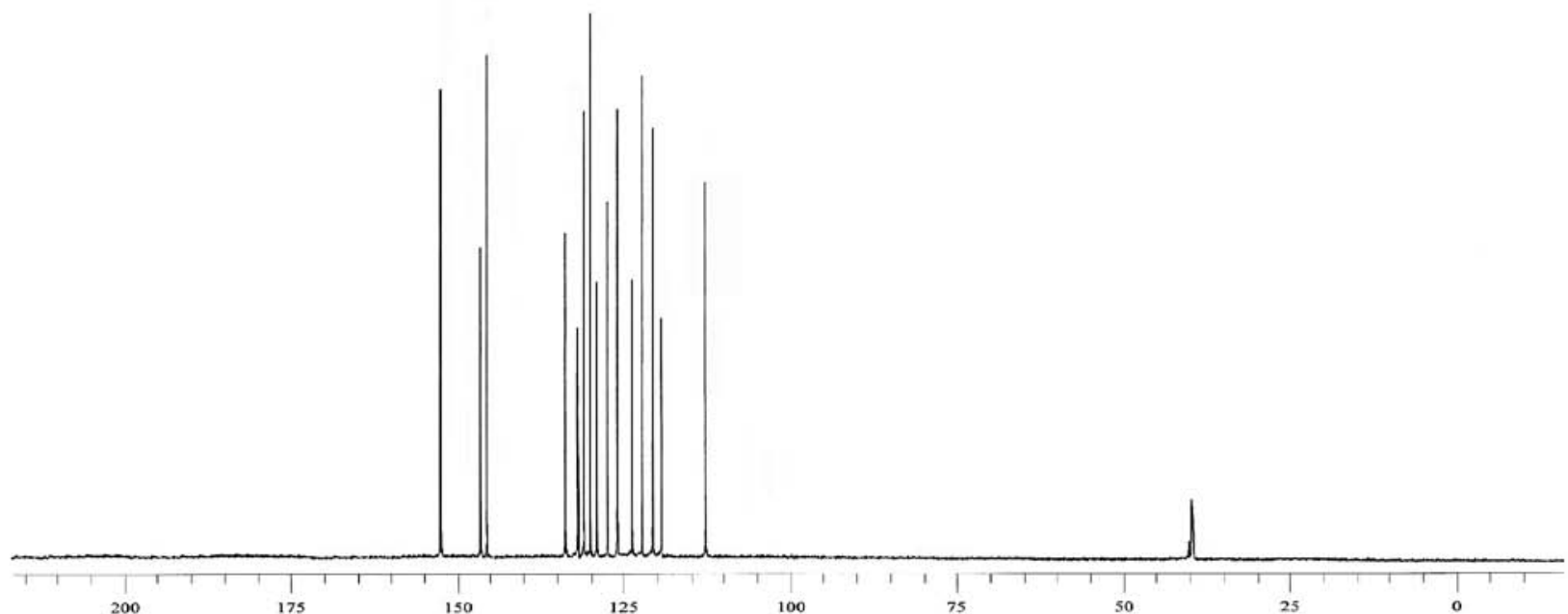

Figure S2. ${ }^{13} \mathrm{C}$ NMR spectrum of 6-phenyl indolo[1,2-c]quinazoline (11). 


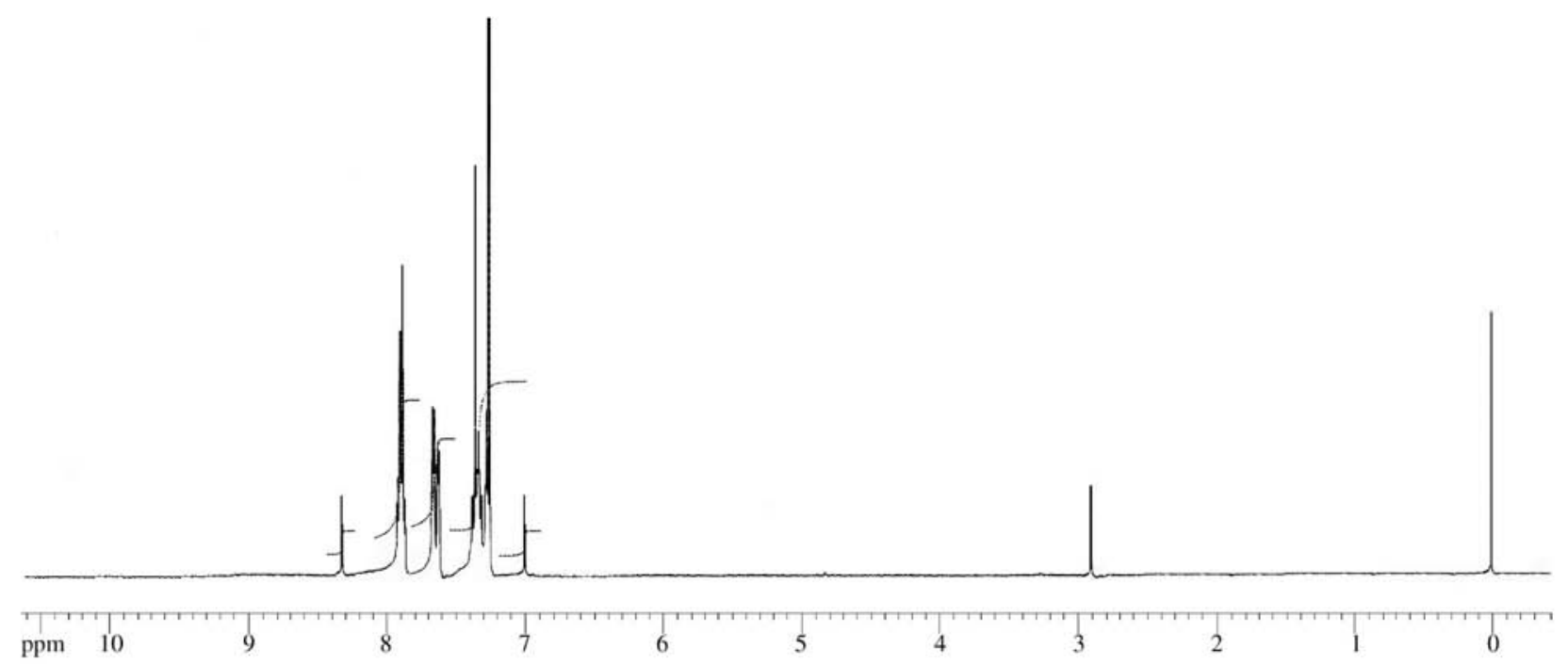

Figure S3. ${ }^{1} \mathrm{H}$ NMR spectrum of 6-phenyl indolo[1,2-c]quinazoline (12).

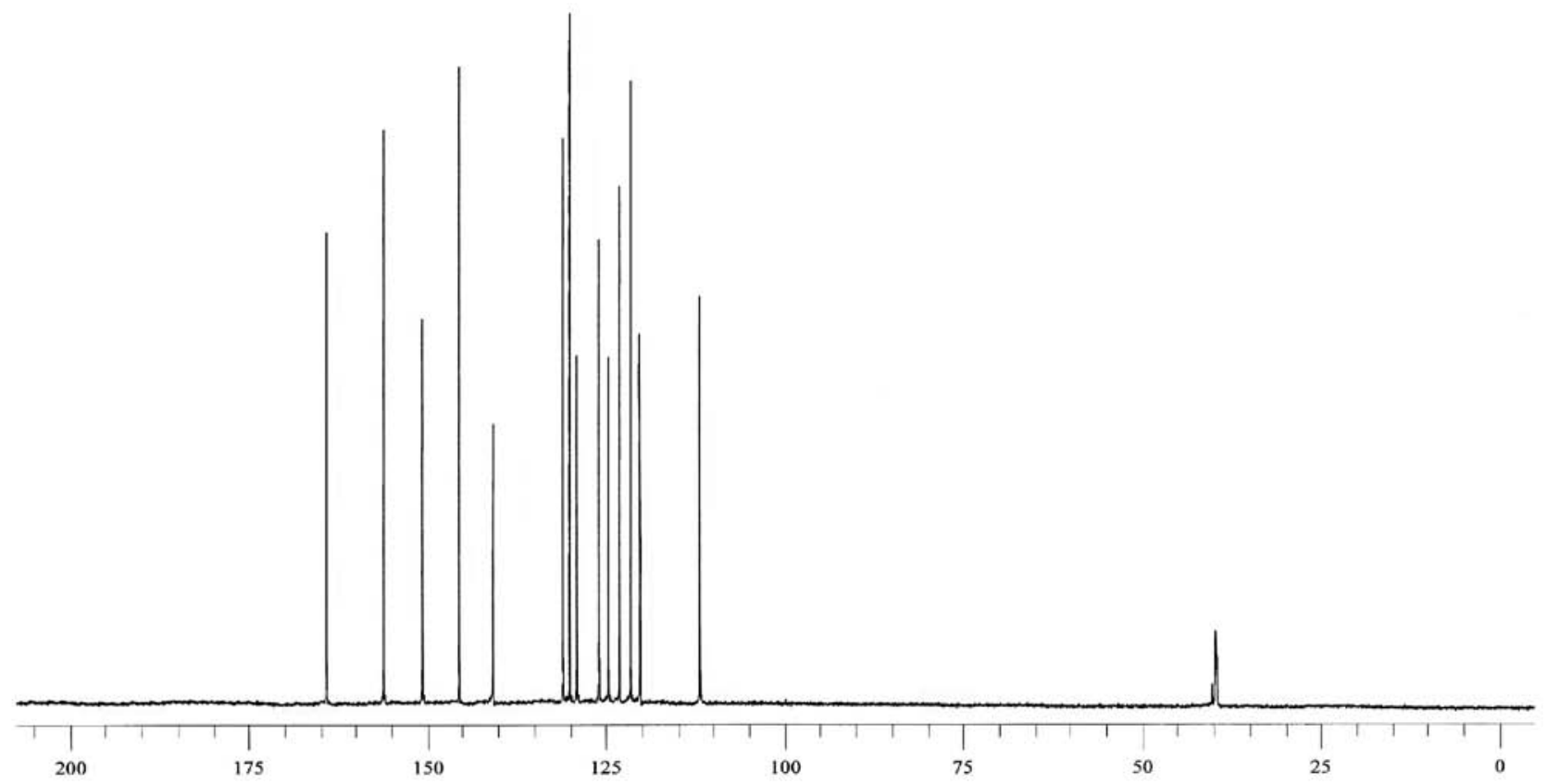

Figure S4. ${ }^{13} \mathrm{C}$ NMR spectrum of 6-phenyl indolo[1,2-c]quinazoline (12). 


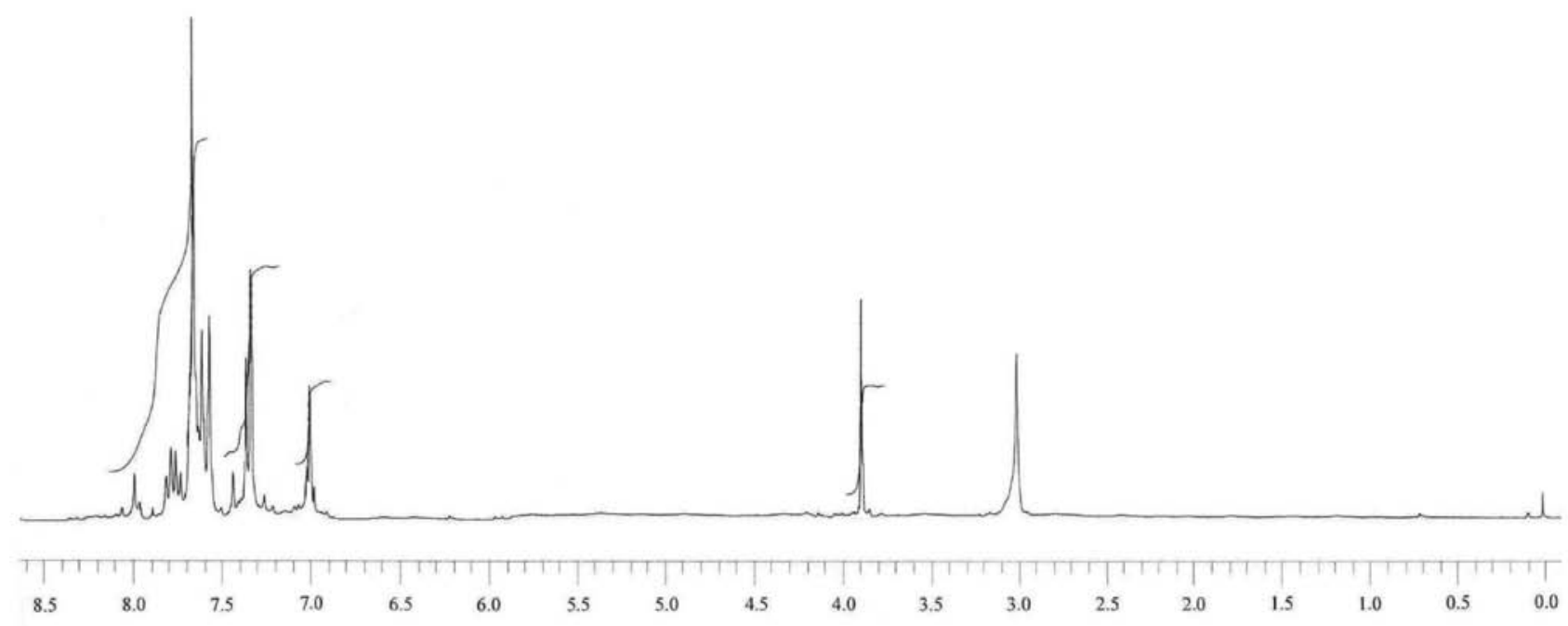

Figure S5. ' ${ }^{1} \mathrm{H}$ NMR spectrum of 6-phenyl indolo[1,2-c]quinazoline (13).

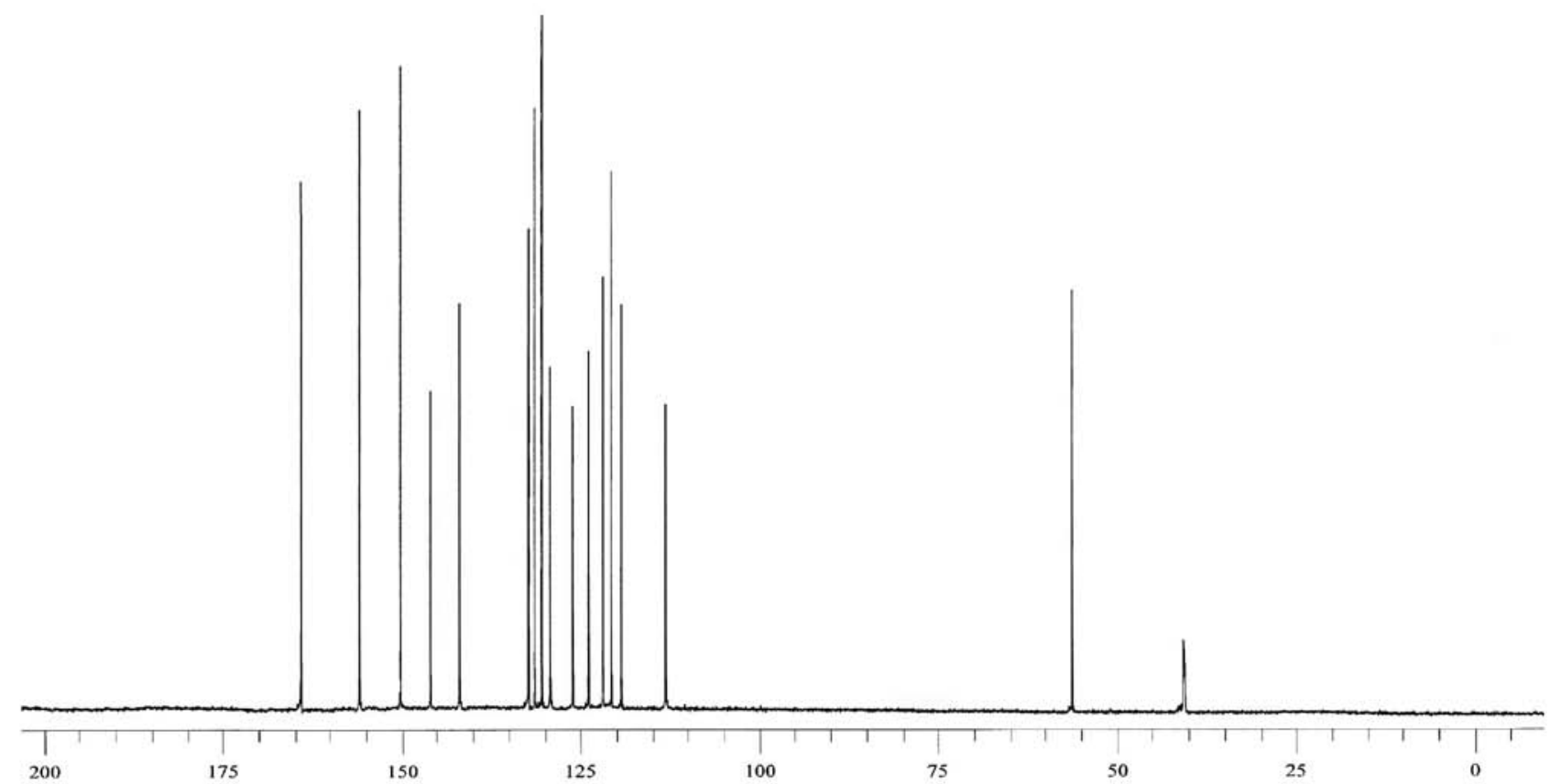

Figure S6. ${ }^{13} \mathrm{C}$ NMR spectrum of 6-phenyl indolo[1,2-c]quinazoline (13). 


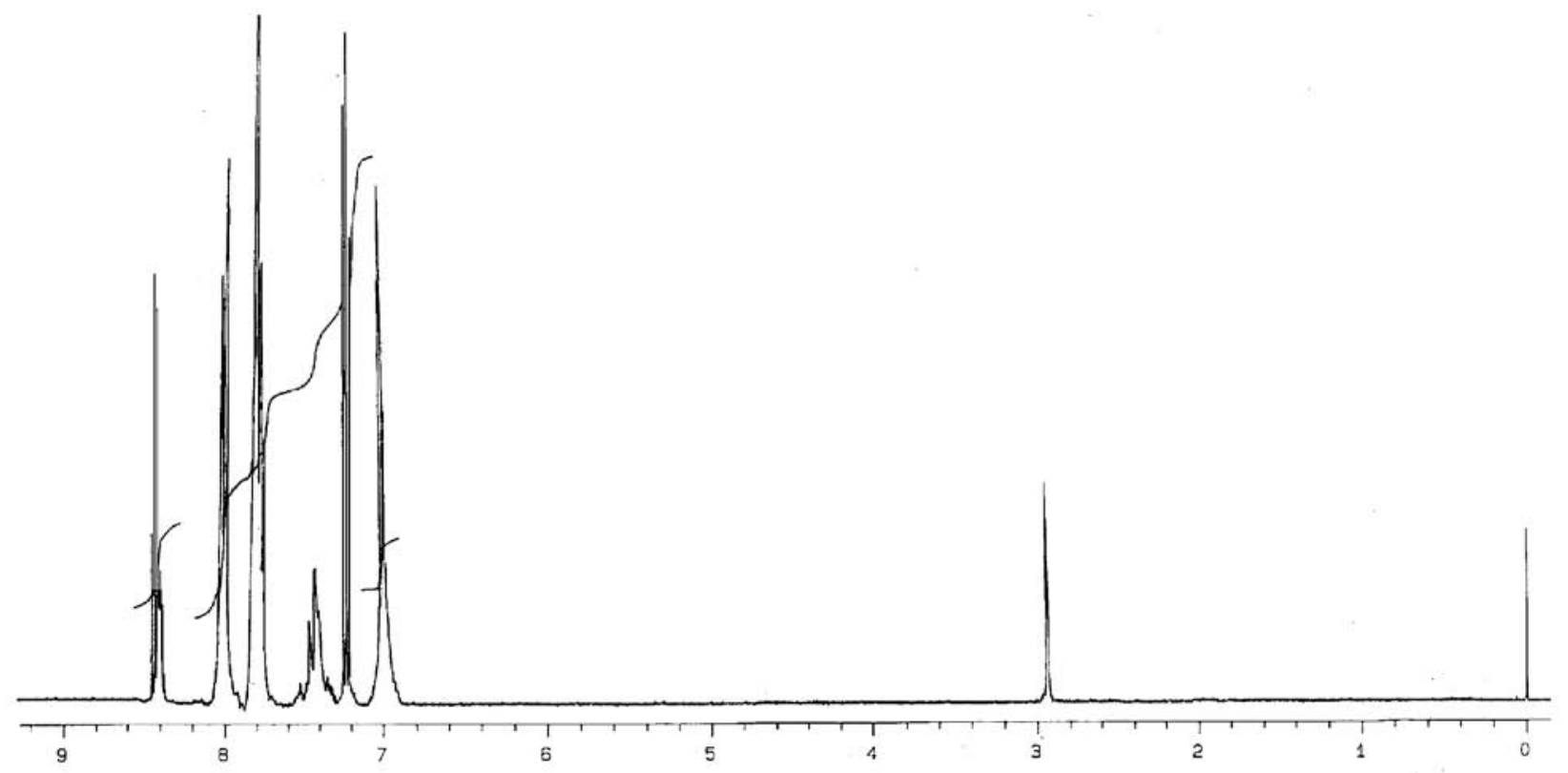

Figure S7. ${ }^{1} \mathrm{H}$ NMR spectrum of 6-phenyl indolo[1,2-c]quinazoline (14).

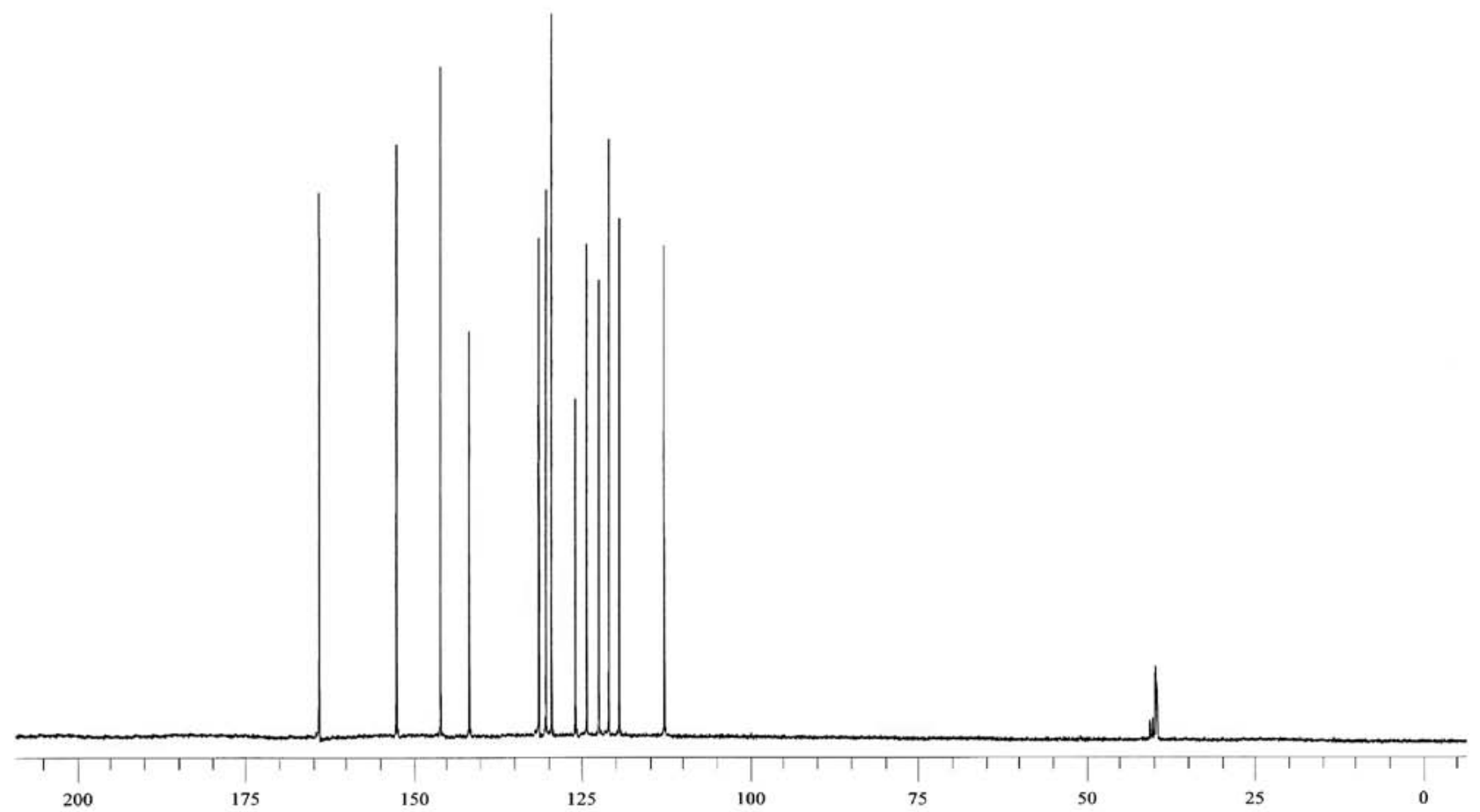

Figure S8. ${ }^{13} \mathrm{C}$ NMR spectrum of 6-phenyl indolo[1,2-c]quinazoline (14). 


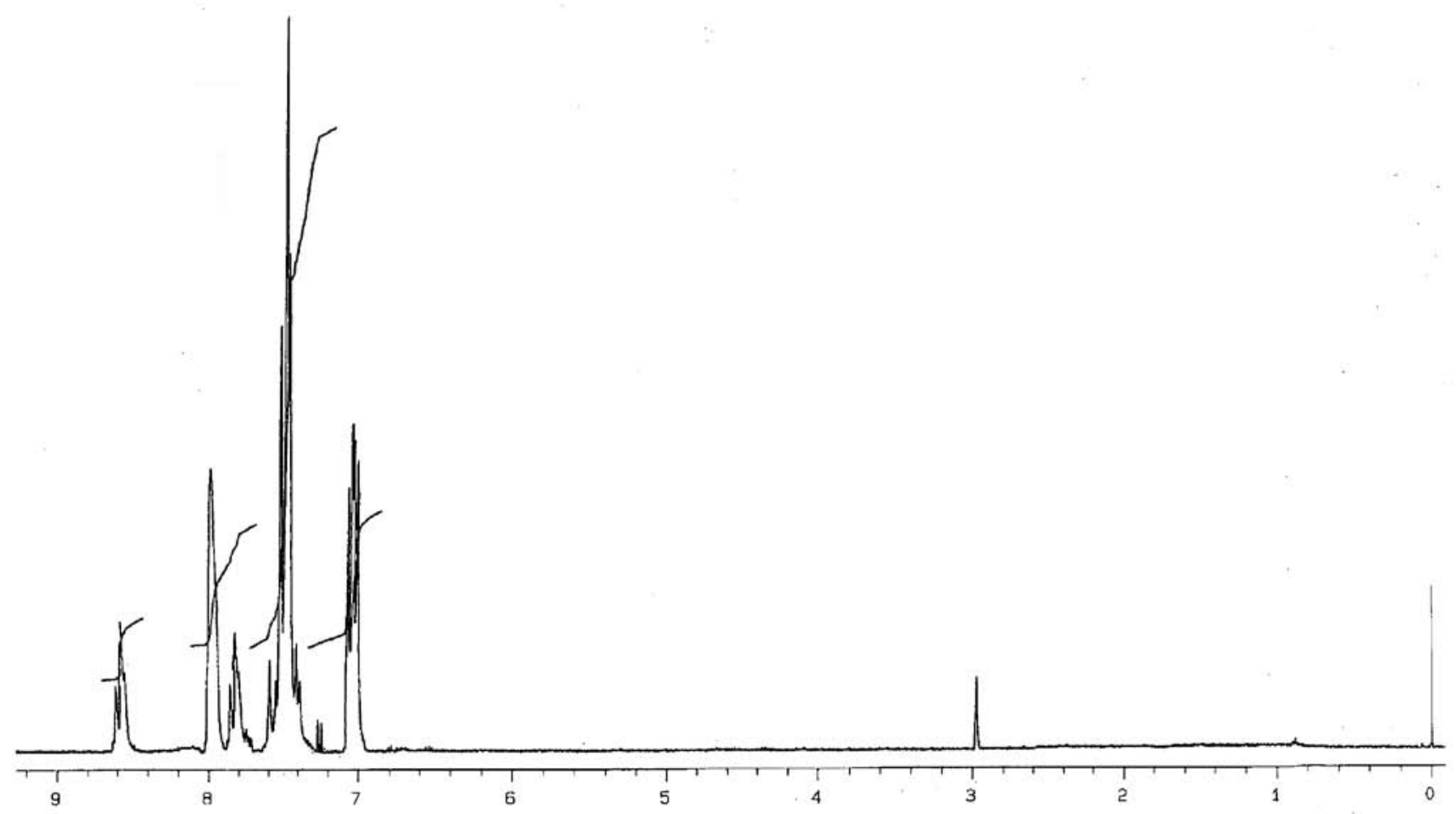

Figure S9. ${ }^{1} \mathrm{H}$ NMR spectrum of 6-phenyl indolo[1,2-c]quinazoline (15).

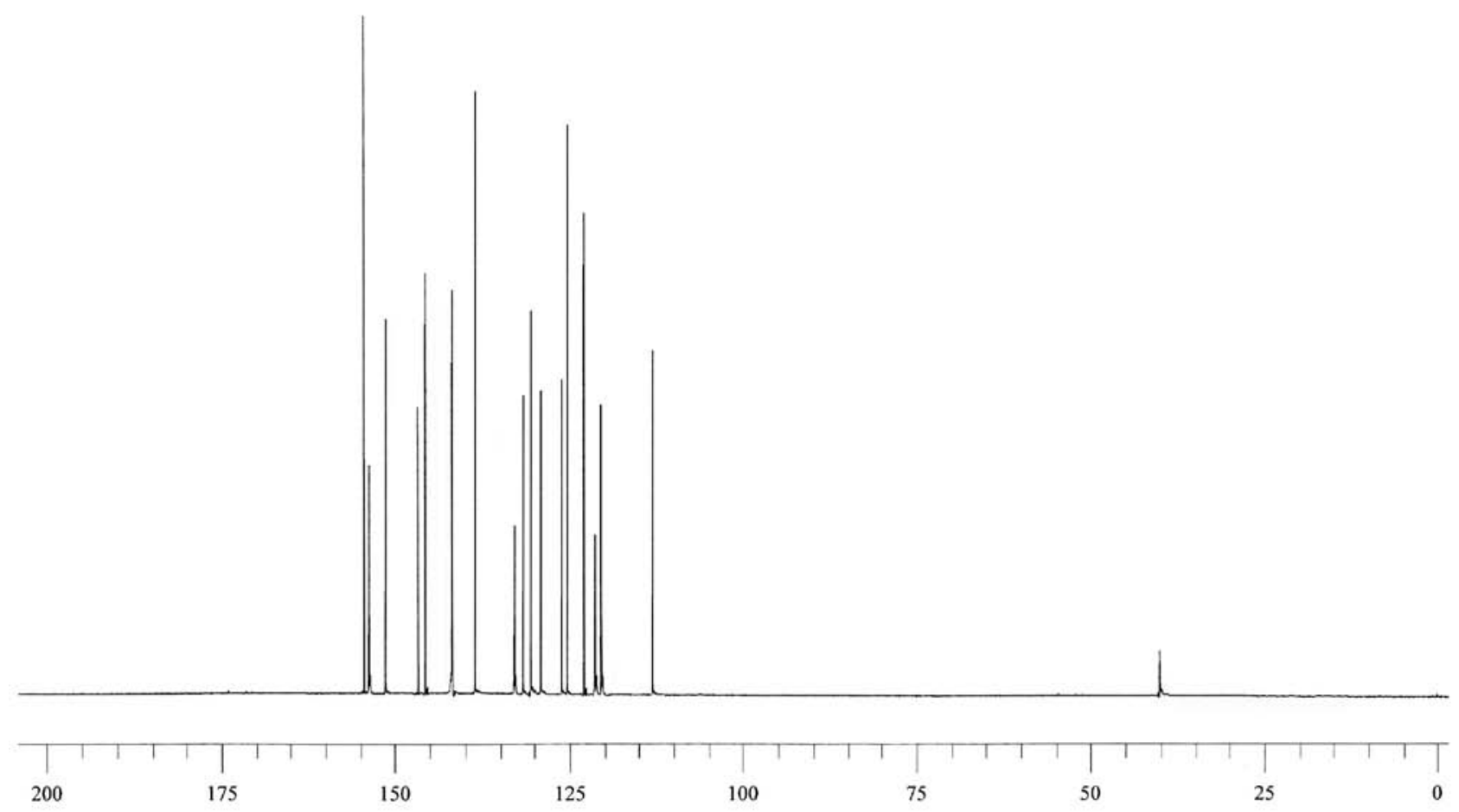

Figure S10. ${ }^{13} \mathrm{C}$ NMR spectrum of 6-phenyl indolo[1,2-c]quinazoline (15). 


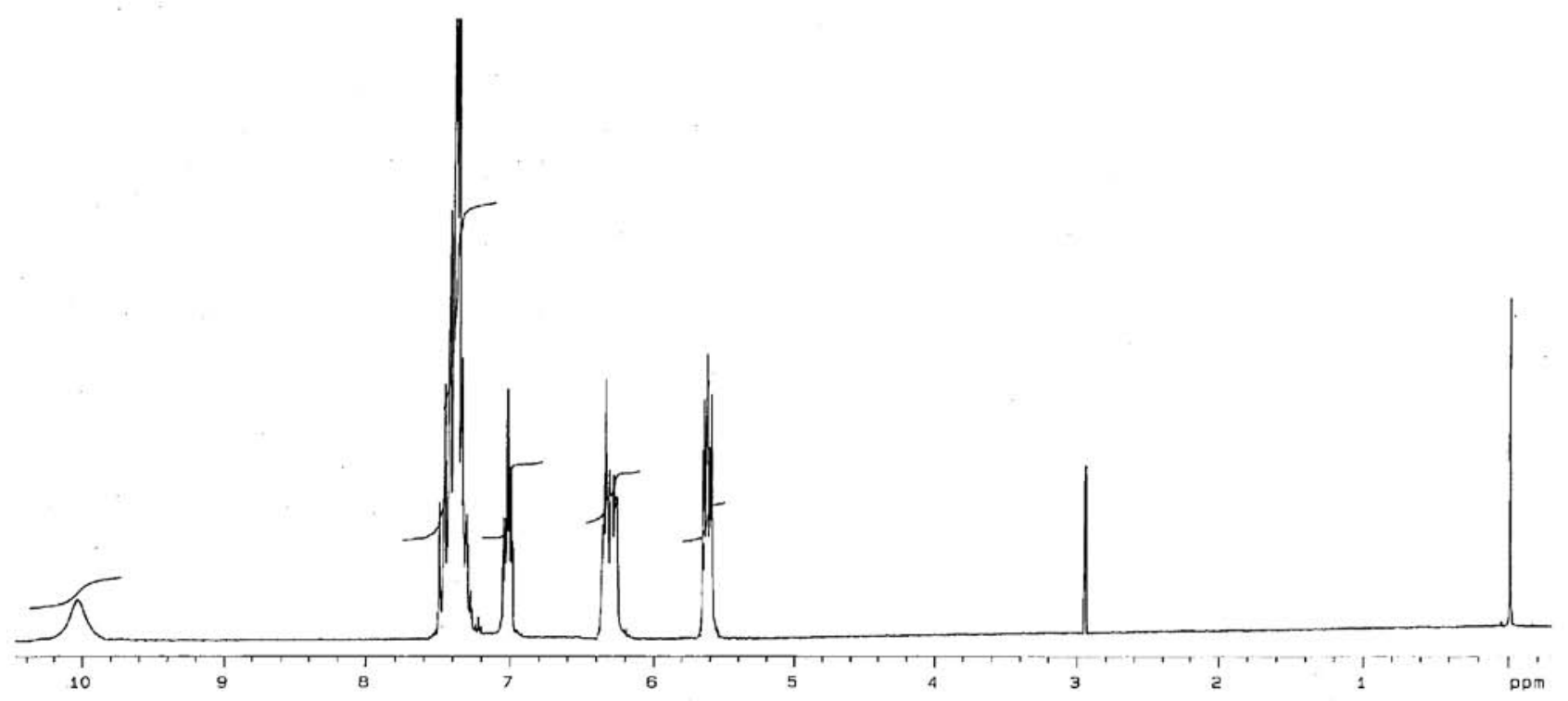

Figure S11. ${ }^{1} \mathrm{H}$ NMR spectrum of 6-phenyl indolo[1,2-c]quinazoline (16).

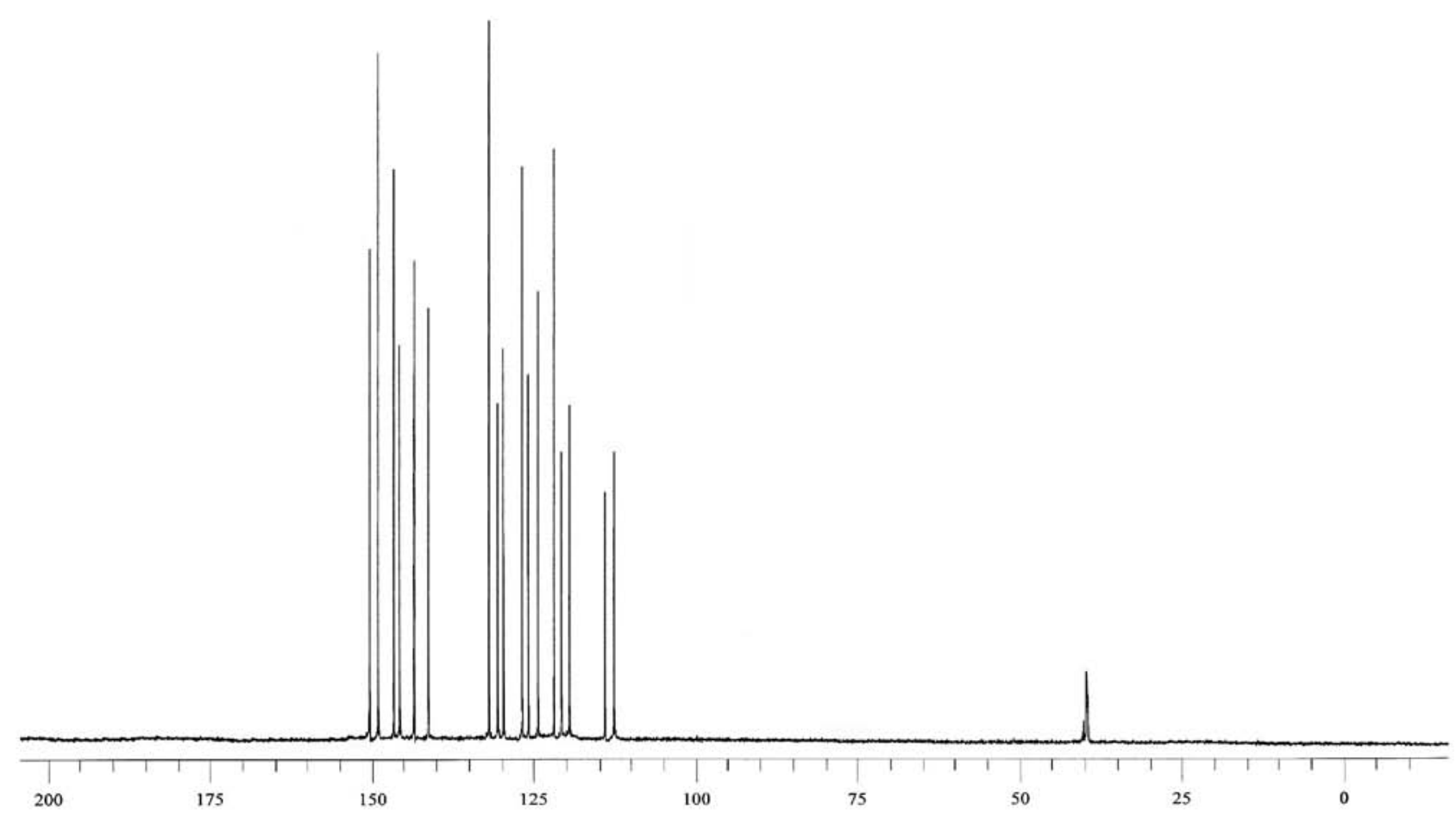

Figure S12. ${ }^{13} \mathrm{C}$ NMR spectrum of 6-phenyl indolo[1,2-c]quinazoline (16). 


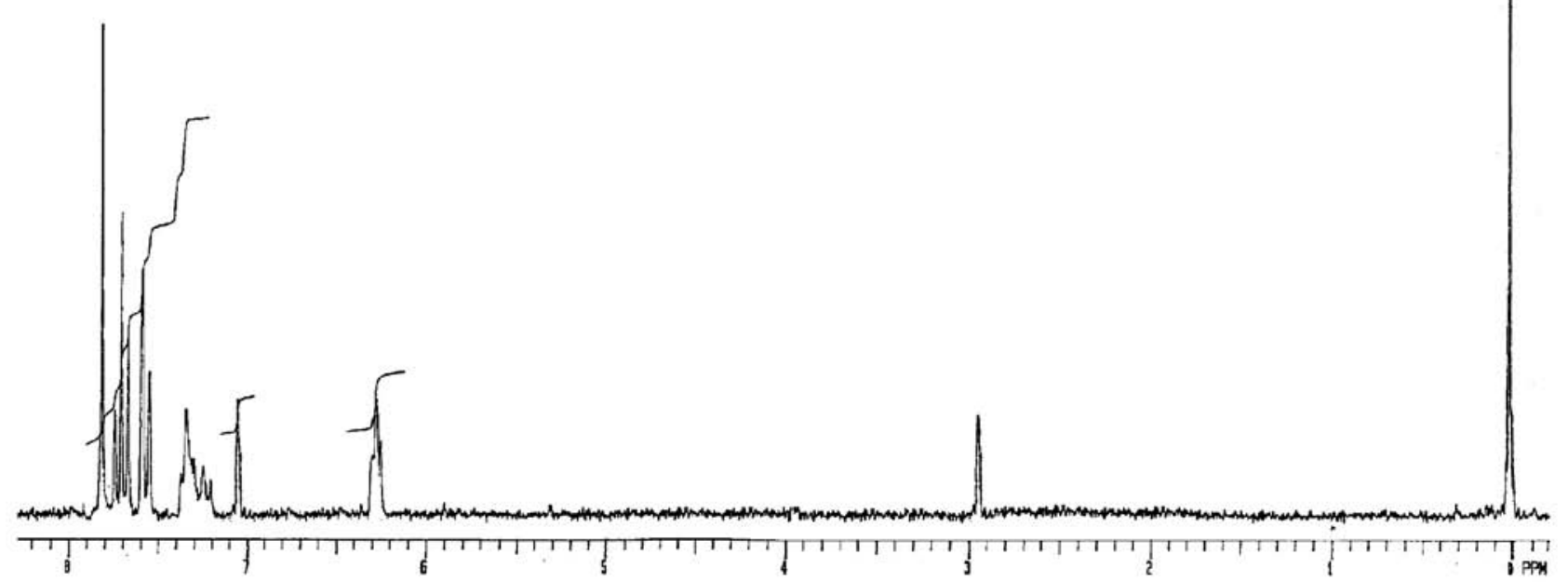

Figure S13. ${ }^{1} \mathrm{H}$ NMR spectrum of 6-phenyl indolo[1,2-c]quinazoline (17).

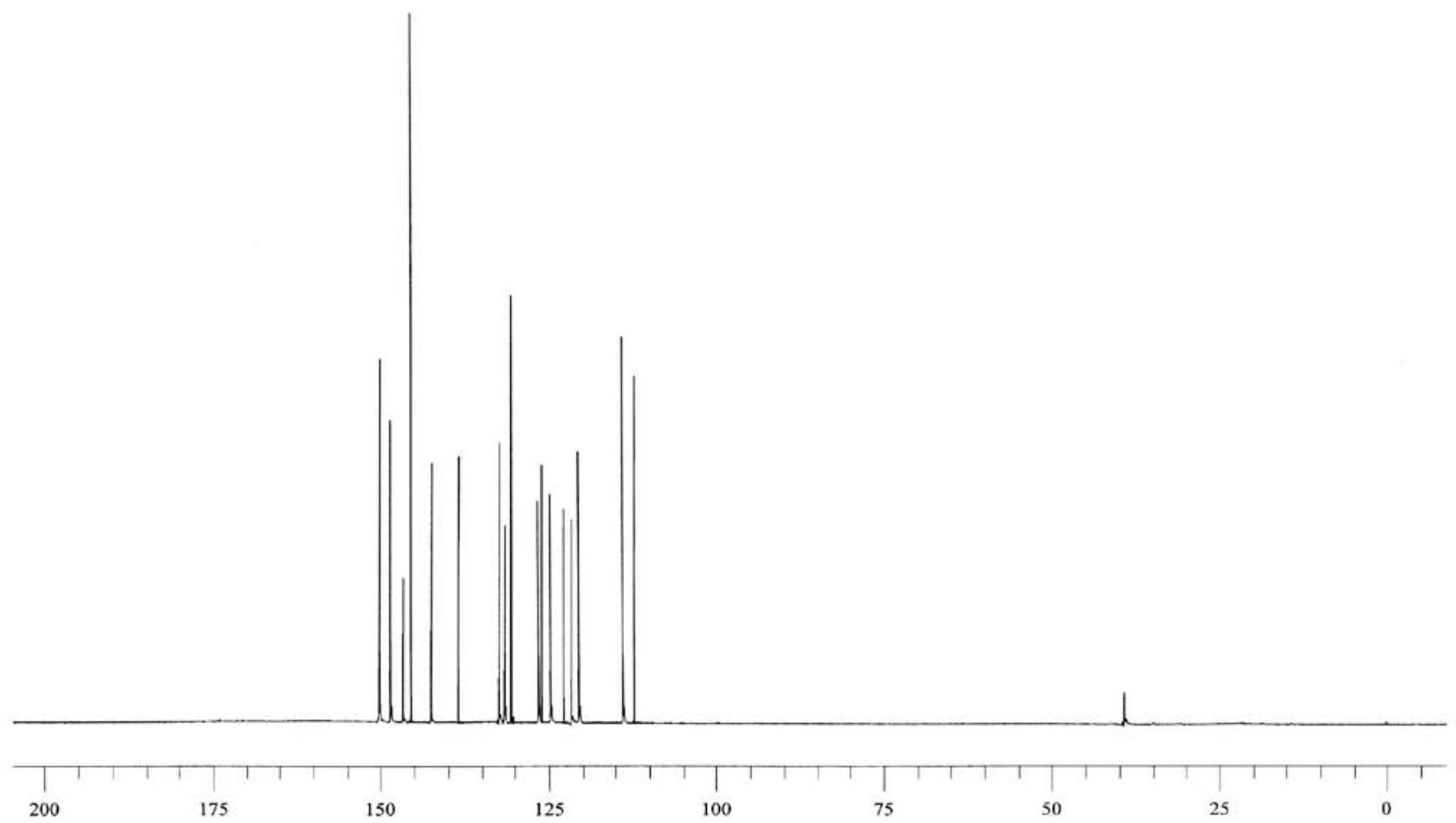

Figure S14. ${ }^{13} \mathrm{C}$ NMR spectrum of 6-phenyl indolo[1,2-c]quinazoline (17). 


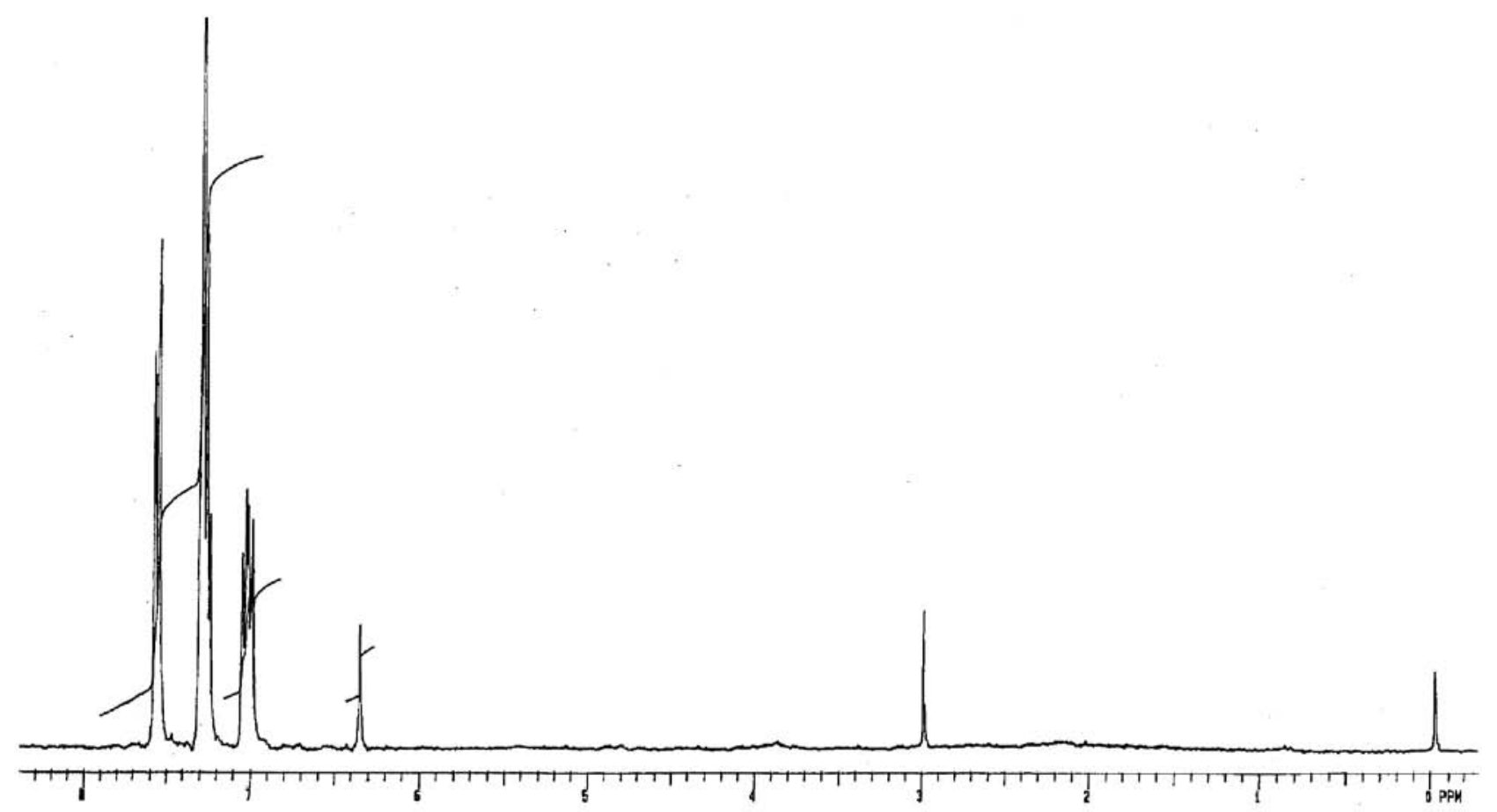

Figure S15. ${ }^{1} \mathrm{H}$ NMR spectrum of 6-phenyl indolo[1,2-c]quinazoline (18).

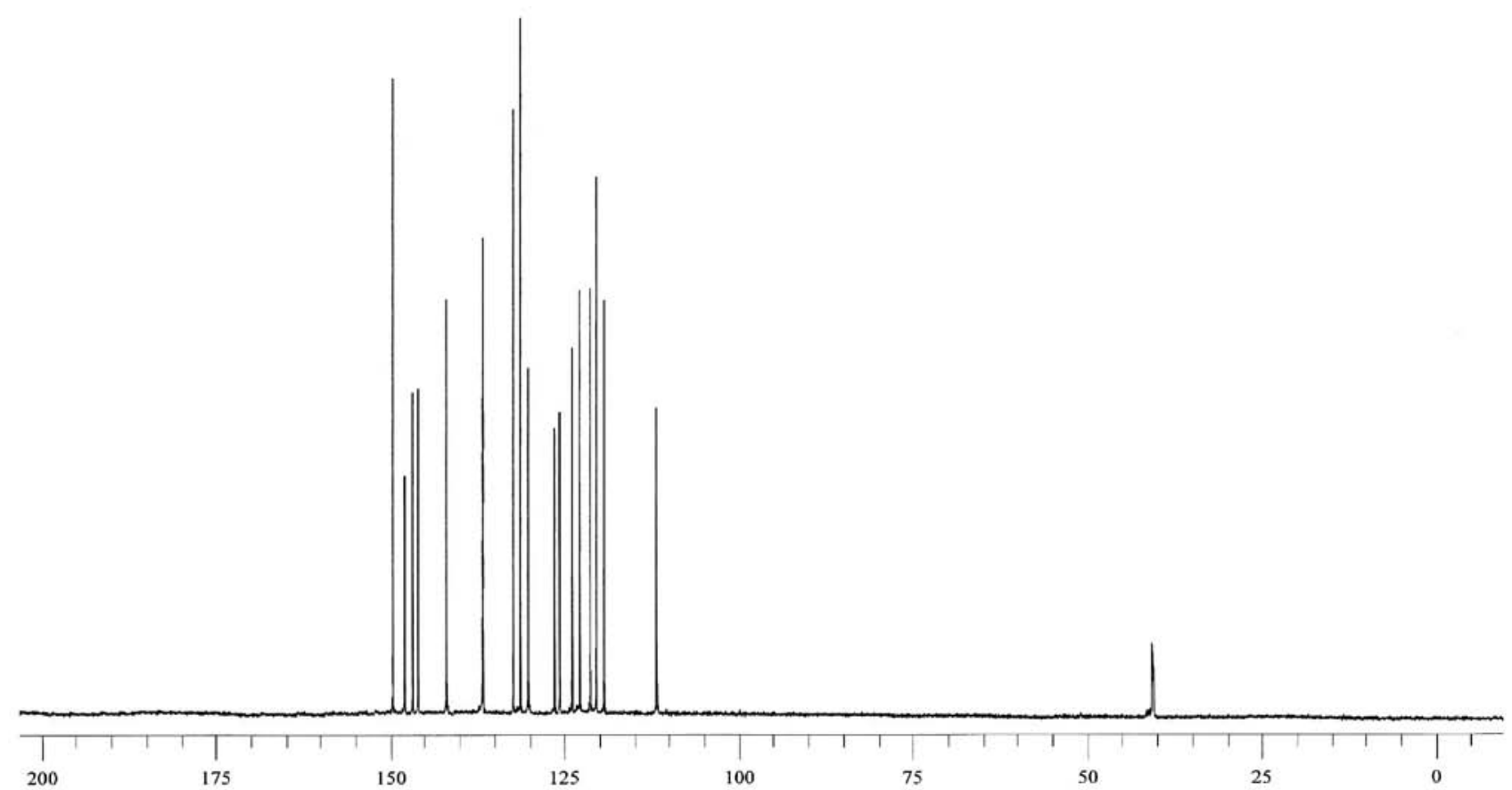

Figure S16. ${ }^{13} \mathrm{C}$ NMR spectrum of 6-phenyl indolo[1,2-c]quinazoline (18). 


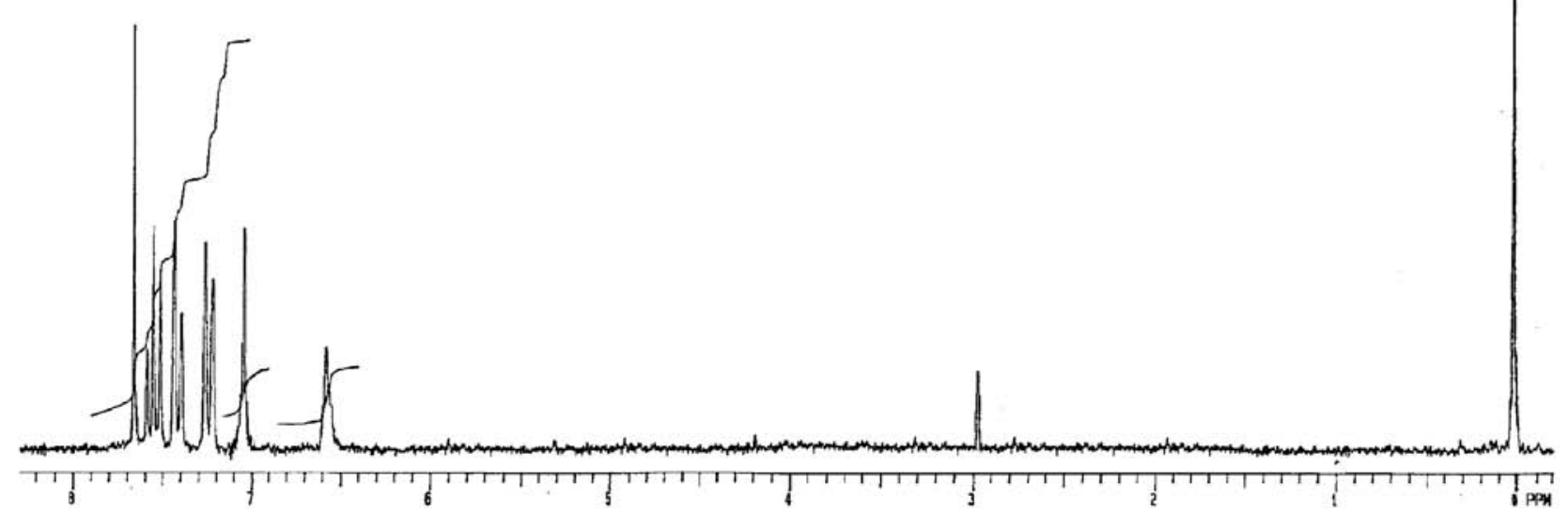

Figure S17. ${ }^{1} \mathrm{H}$ NMR spectrum of 6-phenyl indolo[1,2-c]quinazoline (19).

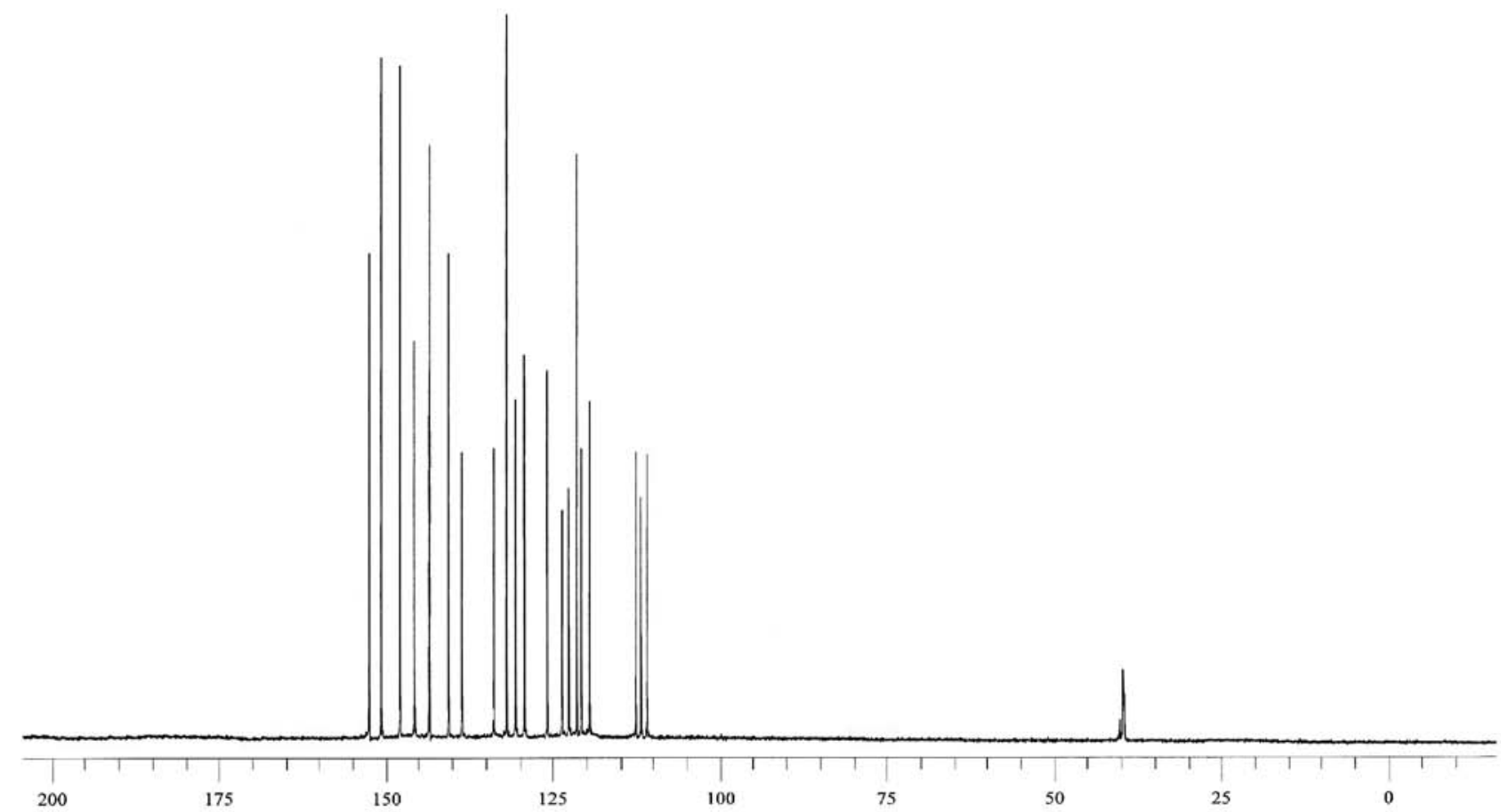

Figure S18. ${ }^{13} \mathrm{C}$ NMR spectrum of 6-phenyl indolo[1,2-c]quinazoline (19). 


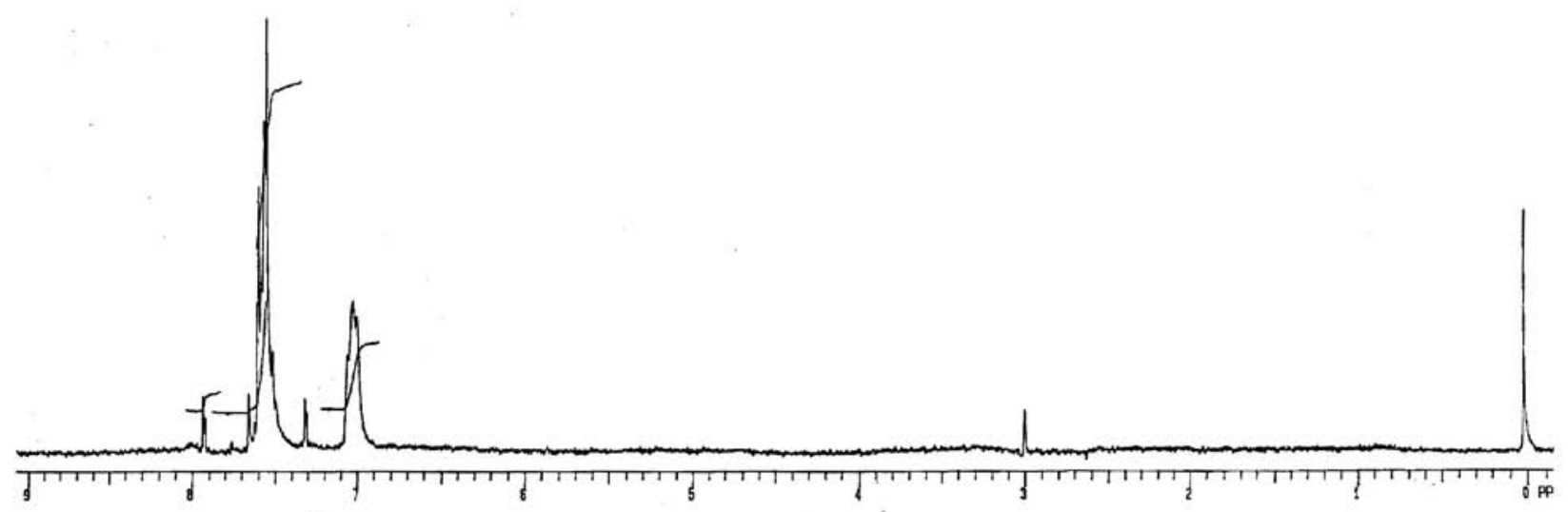

Figure S19. ${ }^{1} \mathrm{H}$ NMR spectrum of 6-phenyl indolo[1,2-c]quinazoline (20).

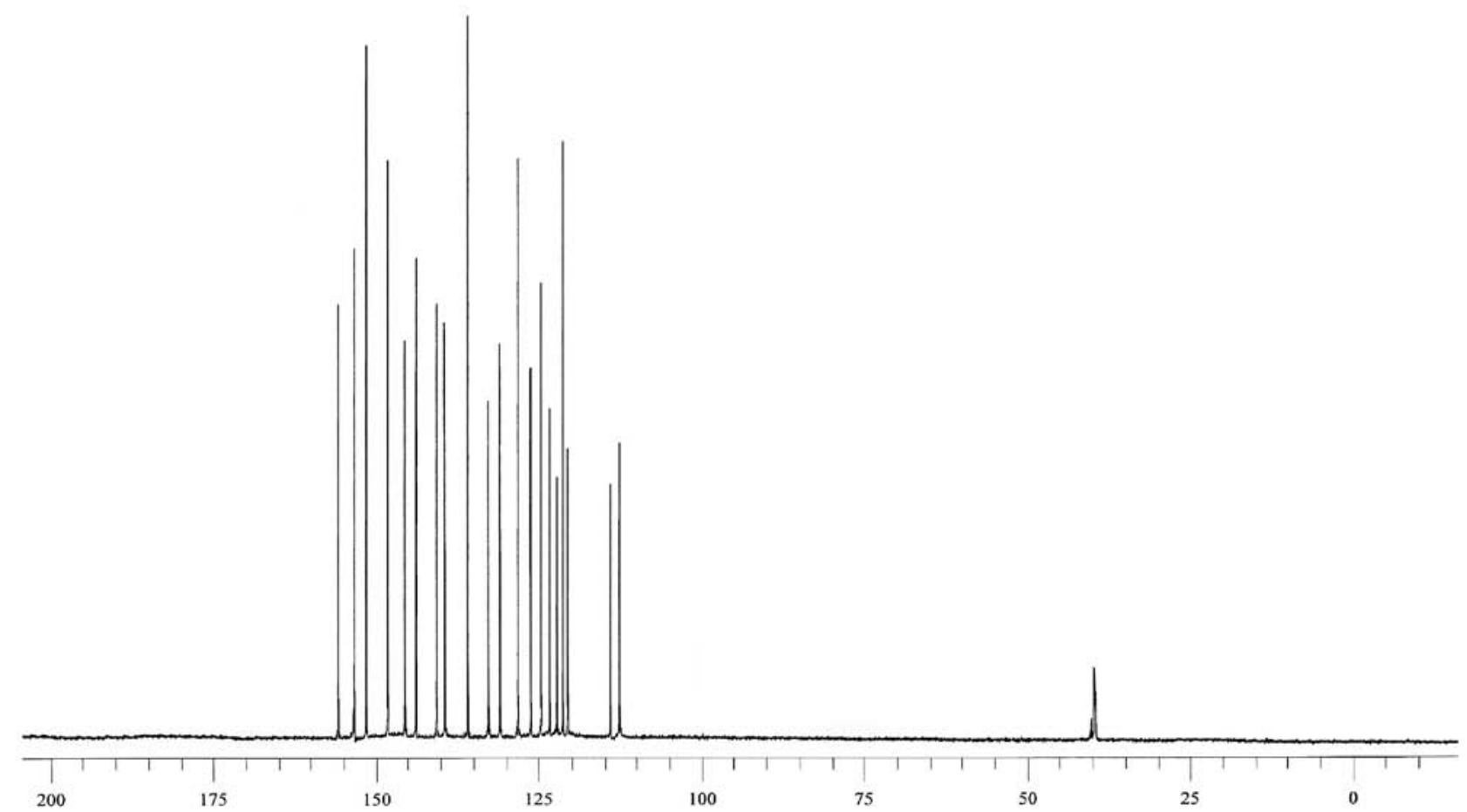

Figure S20. ${ }^{13} \mathrm{C}$ NMR spectrum of 6-phenyl indolo[1,2-c]quinazoline (20). 


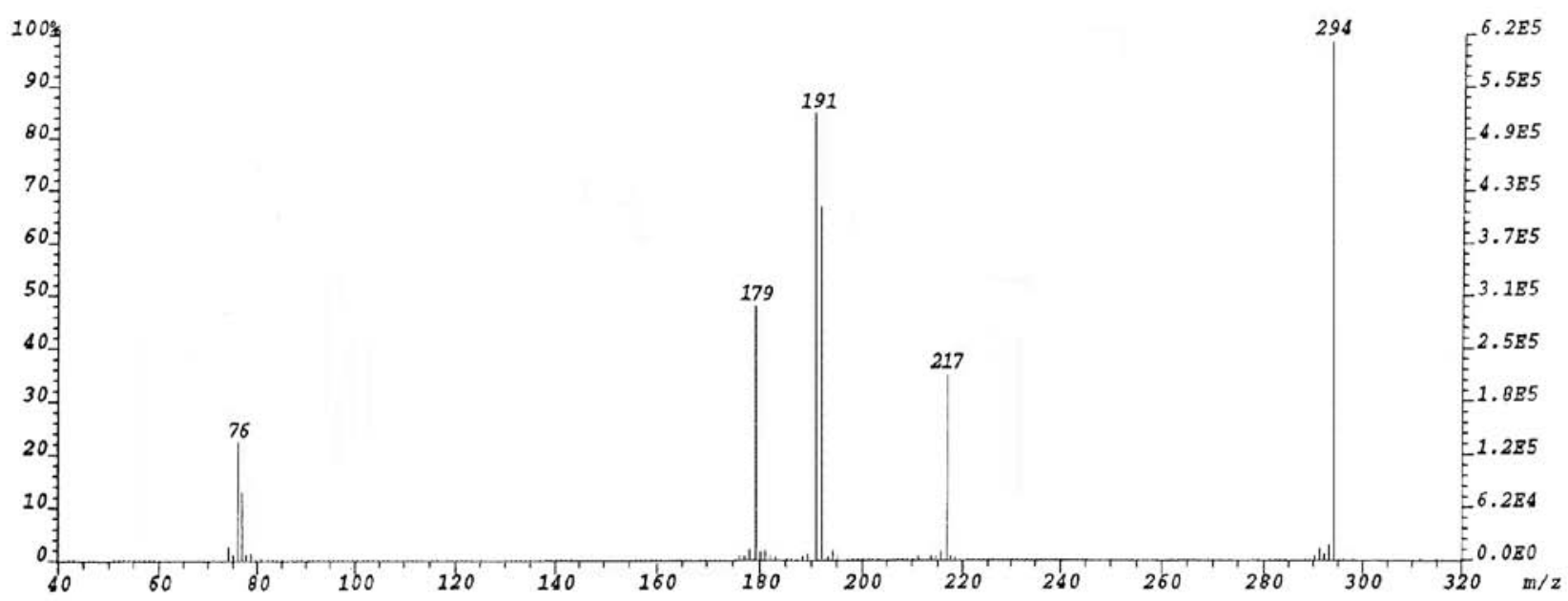

Figure S21. FAB mass spectrum of 6-phenyl indolo[1,2-c]quinazoline (11).<smiles>c1ccc2c(c1)cc1c3ccccc3ncn21</smiles>

$m / z 217$

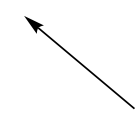<smiles>[C+]1=CC=CC=C1</smiles><smiles>[CH]1CCC1</smiles>

$\mathrm{m} / 277$

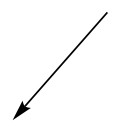<smiles>c1ccc(-c2cc3ccccc3[nH]2)cc1</smiles>

$m / z 192$

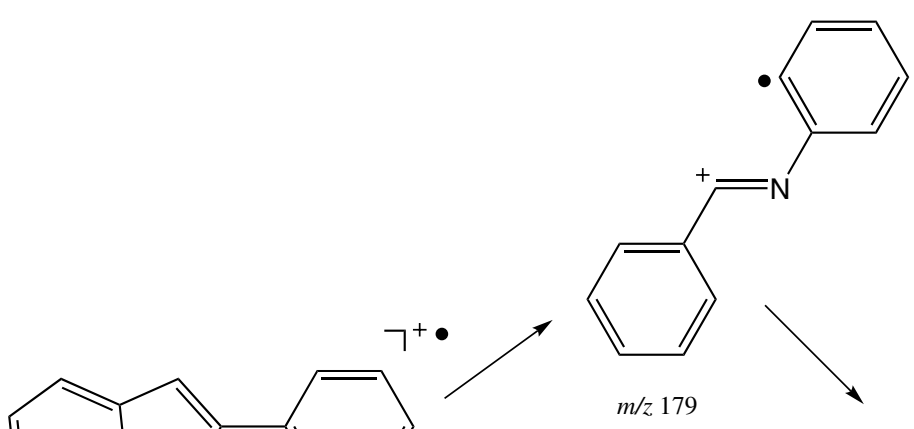<smiles>c1ccccc1</smiles>

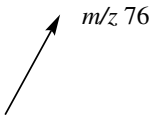

$m / z 294$

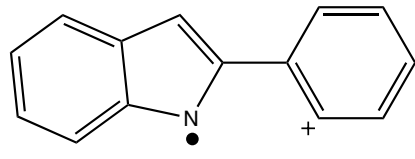

$m / z 191$

Scheme S1. FAB mass fragmentation pattern of 6-phenyl indolo[1,2-c]quinazoline (11). 